Article

\title{
Organic Zinc Salts as Pro-Ecological Activators for Sulfur Vulcanization of Styrene-Butadiene Rubber
}

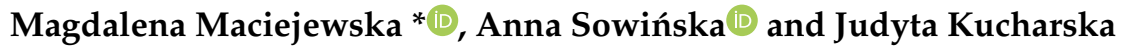 \\ Institute of Polymer and Dye Technology, Lodz University of Technology, Stefanowskiego Street 12/16, \\ 90-924 Lodz, Poland; anna.sowinska@edu.p.lodz.pl (A.S.); 204352@edu.p.lodz.pl (J.K.) \\ * Correspondence: magdalena.maciejewska@p.lodz.pl
}

Received: 20 September 2019; Accepted: 19 October 2019; Published: 21 October 2019

\begin{abstract}
Organic zinc salts and complexes were applied as activators for sulfur vulcanization of styrene-butadiene elastomer (SBR) in order to reduce the content of zinc ions in rubber compounds as compared with conventionally used zinc oxide. In this article, the effects of different organic zinc activators on the curing characteristics, crosslink densities, and mechanical properties of SBR as well as the aging resistance and thermal behavior of vulcanizates are discussed. Organic zinc salts seem to be good substitutes for zinc oxide as activators for sulfur vulcanization of SBR rubber, without detrimental effects to the vulcanization time and temperature. Moreover, vulcanizates containing organic zinc salts exhibit higher tensile strength and better damping properties than vulcanizate crosslinked with zinc oxide. The application of organic zinc activators allows the amount of zinc ions in SBR compounds to be reduced by 70-90 wt \% compared to vulcanizate with zinc oxide. This is very important for ecological reasons, since zinc oxide is classified as being toxic to aquatic species.
\end{abstract}

Keywords: organic zinc salts; activator; vulcanization; rubber; zinc oxide

\section{Introduction}

Zinc oxide $(\mathrm{ZnO})$ is widely used as an activator in the vulcanization of unsaturated elastomers by sulfur or sulfur donors. As a result, the amount of bound sulfur and the efficiency of the crosslinking system are enhanced. Moreover, zinc oxide reduces the vulcanization time of rubber compounds and improves the processing and physical properties of vulcanizates [1]. It also used as a crosslinking agent of elastomers containing suitable functional groups, such as carboxylated and chloroprene rubbers [2-4] or chlorosulfonated polyethylene [5]. Furthermore, $\mathrm{ZnO}$ is used as a filler of rubber composites intended for products exhibiting increased heat conductivity [6]. Despite the important role of $\mathrm{ZnO}$ in sulfur vulcanization, its concentration in rubber compounds, especially those used in aquatic environments, must be reduced to, at least, below $2.5 \mathrm{wt} \%$, because zinc oxide is classified as being toxic to aquatic life. According to European Union Regulation (EC) No 1272/2008 on classification, labeling and packaging of substances and mixtures, $\mathrm{ZnO}$ was classified as Aquatic Acute 1 with hazard statement H400: Very toxic to aquatic life and Aquatic Chronic 1 with hazard statement H410: Very toxic to aquatic life with long lasting effects. The precaution recommended in this Regulation is defined as P273: Avoid release to the environment. The release of zinc from rubber products occurs during their manufacture, use (dust created during the abrasion of tires on road surfaces) and the recycling or disposal in landfills. A potential source of zinc in groundwater can also be rubber granulates made from end-of-life tires used to build artificial sports fields. Taking this into account, the problem of reducing the amount of zinc in rubber products becomes essential. Methods to reduce the amount of $\mathrm{ZnO}$ in elastomers have been widely studied. Chapman and Johnson [7] replaced traditionally used microsized $\mathrm{ZnO}$ with more active forms of zinc oxide characterized by a high surface area or very small particle size. This allowed for the reduction of $\mathrm{ZnO}$ content to 2 parts per hundred of rubber (phr) 
in ethylene-propylene-diene monomer rubber (EPDM) or natural rubber (NR) compounds. Further reduction of the zinc oxide level led to reversion during vulcanization and deterioration of mechanical properties such as the modulus or compression set of vulcanizates.

Pysklo et al. [8] reported that the amount of $\mathrm{ZnO}$ can be reduced in carbon black-filled polyisoprene rubber (IR) to $2 \mathrm{phr}$ and in styrene-butadiene elastomer (SBR) compounds to $1 \mathrm{phr}$ without affecting the vulcanization kinetics and mechanical properties of the vulcanizates. The crown ether 18-crown- 6 was used as the interface transfer catalyst to increase the rate and efficiency of the crosslinking reaction. Lower than 1-2 phr content of $\mathrm{ZnO}$ significantly increased the reversion during vulcanization.

Maciejewska and Zaborski [9] used zinc oxide nanoparticles to reduce the content of $\mathrm{ZnO}$ in acrylonitrile-butadiene elastomer (NBR) filled with nanosized silica. Replacing $5 \mathrm{phr}$ of microsized $\mathrm{ZnO}$ with $2 \mathrm{phr}$ of zinc oxide nanopowder did not affect the curing behavior of NBR and consequently the crosslink density or tensile properties of vulcanizates. Moreover, vulcanizates with nanosized $\mathrm{ZnO}$ demonstrate better damping properties and higher thermal stability compared with the vulcanizate that contains a standard activator.

Kim et al. incorporated nanosized $\mathrm{ZnO}$ instead of conventional $\mathrm{ZnO}$ into $\mathrm{NR} /$ butadiene rubber (BR) compounds filled with silica [10]. NR/BR composites containing 0.3-3 phr of nanosized ZnO showed improved cure characteristics, lower optimum vulcanization time, higher tensile strength and tear strength compared to the composite crosslinked with $5 \mathrm{phr}$ of microsized $\mathrm{ZnO}$.

According to the generally accepted mechanism of sulfur vulcanization, zinc cations from $\mathrm{ZnO}$ react with accelerators, forming active zinc-accelerator complexes, which are believed to be more reactive than free accelerators [1,11,12]. In order to increase the activity of $\mathrm{ZnO}$ at this step of vulcanization, the availability of zinc ions for reaction with the accelerator should be increased. Owing to the crystalline structure of $\mathrm{ZnO}$, zinc ions inside the crystals have limited accessibility. Therefore, to reduce the amount of zinc ions in rubber compounds, it is necessary to apply more chemically active zinc, in the form of reactive complexes, in which the availability of zinc ions is higher than in the crystals of $\mathrm{ZnO}$.

Heideman et al. used zinc stearate, zinc 2-ethylhexanoate, and zinc m-glycerolate to activate the sulfur vulcanization of EPDM and styrene-butadiene elastomer (SBR) [13]. The highest vulcanization activity is exhibited by zinc $\mathrm{m}$-glycerolate which has the highest amount of zinc ions per $1 \mathrm{~g}$ of activator. It seems to be a good substitute for $\mathrm{ZnO}$ without detrimental effects on the crosslinking degree of elastomers, their mechanical properties, and resistance to thermo-oxidative aging. However, it should be noted that in the case of rubber compounds crosslinked with zinc m-glycerolate, the content of zinc ions is higher than in the rubber compound containing $\mathrm{ZnO}$, so no reduction in the zinc amount is achieved. Other zinc complexes show lower efficiency as activators than $\mathrm{ZnO}$, probably due to the considerably lower content of zinc ions introduced into rubber corresponding to $\mathrm{ZnO}$. They result in a much lower crosslinking degree of elastomers compared with the compound containing zinc oxide.

Another approach to reduce the amount of zinc oxide in rubber compounds is the development of zinc loaded clay (Zn-clay) as a vulcanization activator with improved zinc ion accessibility [14]. This activator consists of montmorillonite clay into which zinc ions are introduced via the ion exchange process. Zn-clay achieves comparable SBR curing characteristics, crosslinking degree, and mechanical properties to the conventional system with zinc oxide. The content of zinc ions in the SBR compounds is reduced by a factor of 10-20 compared with the $\mathrm{ZnO}$ activator.

Przybyszewska et al. developed new zinc chelates with 1,3-diketones as activators for the sulfur vulcanization of NBR. These chelates are synthesized using commercially available diketones, according to a simple procedure [15]. The application of zinc chelates in the crosslinking process provides vulcanizates with crosslink densities similar to those with $2 \mathrm{phr}$ of nanosized $\mathrm{ZnO}$. This reduced the amount of zinc ions applies by more than $70 \mathrm{wt} \%$ compared with nanosized zinc oxide. Moreover, the most active zinc chelates, such as zinc 1,3-diphenylpropane-1,3-dione and zinc 1-(4'-t-butylphenyl)-3-phenylpropane-1,3-dione, considerably reduce the optimal time of NBR vulcanization and allow vulcanizates with significantly higher tensile strength and elasticity to be 
obtained compared to using nanosized $\mathrm{ZnO}$. However, despite the high activity of zinc chelates with 1,3-diketones, the necessity of synthesis is a limitation on their use on a larger scale.

In this work, we applied commercially available organic zinc salts and complexes, such as zinc gluconate (GluZn), zinc ricinoleate (RicZn), and zinc acetylacetonate (AAcZn) to activate the sulfur crosslinking of SBR rubber. The goal of this research was to develop pro-ecological substitutes for zinc oxide that allow for a reduction in the amount of zinc ions in the rubber compounds.

Pursuant to the (EC) No 1272/2008 Regulation, AAcZn is not considered as a substance harmful to the environment. It is widely used in polymer technology as an initiator for lactide polymerization [16] and for polymerization of 1,3-trimethylene carbonate or 2,2-dimethyltrimethylene carbonate resulting in the production of polycarbonates for medical applications (e.g., medical implants) [17]. AAcZn is also used as a curing catalyst and modifier of epoxy resins [18]. On the other hand, GluZn has been classified by U.S. Food and Drug Administration (FDA) as a generally recognized as safe (GRAS) substance-Subpart I-Nutrients [19]. It is commonly used as a one of the most effective zinc supplements to treat and to prevent zinc deficiency [20]. GluZn is thought to be an antiviral agent or cosmetic biocide effective for use in cosmetics and personal care products. Besides, GluZn can be administrated in pharmaceutical doses in adjunctive therapy of inflammatory acne [21], immune disturbances and common cold [22], dysgeusia [23] or olfactory disorders [24]. Regarding RicZn, it has a very good ability for the adsorption of odor-active compounds, so it is widely used as an odor-removing agent in cosmetic and hygienic applications, such as in surfactant and detergent mixtures, deodorants, perfumes, and toilet preparations [25,26]. Kuhn et al. [27] reported that RicZn exhibits excellent selectivity for organic sulfur and nitrogen compounds. It is able to bind these molecules chemically resulting in the removal of unpleasant odor-active substances from the ambient air. This property of RicZn is also important for its use as a vulcanization activator because most vulcanization accelerators are sulfur and nitrogen compounds. Owing to cosmetic and hygienics applications, the toxicological and dermatological properties of RicZn have been studied. The Cosmetic Ingredient Review (CIR) Expert Panel has classified RicZn as safe and has recommend its use as an anticaking agent, deodorant, and opacifying agent [28].

Therefore, we proposed to use the organic zinc complexes and salts as a pro-ecological alternative for zinc oxide. These compounds were classified as safe and are commonly used even in products approved for contact with human body. Moreover, these organic zinc salts contain less amount of zinc in $1 \mathrm{~g}$ of the compound, so the amount of zinc released into the environment from rubber products should decrease significantly. It is believed that organic zinc activators can be dispersed more easily in the elastomer matrix than microsized $\mathrm{ZnO}$, and therefore, the accessibility of zinc ions for reaction with the accelerator is higher, although applications of such organic zinc compounds as activators of SBR vulcanization have not yet been reported.

\section{Materials and Methods}

\subsection{Materials}

SBR (KER 1500) rubber containing $23.5 \%$ bonded styrene was obtained from Synthos SA (Oswiecim, Poland). Its Mooney viscosity was ML1+4 $\left(100^{\circ} \mathrm{C}\right)$ : 50 . SBR rubber was cured using a conventional curing system containing sulfur (Siarkopol, Tarnobrzeg, Poland) in the presence of 2-mercaptobenzothiazole (MBT) and N-cyclohexyl-2-benzothiazolesulfenamide (CBS) as accelerators (Sigma-Aldrich, Schelldorf, Germany). Microsized zinc oxide $(\mathrm{ZnO})$ with a specific surface area of $10 \mathrm{~m}^{2} \cdot \mathrm{g}^{-1}$ (Huta Bedzin, Bedzin, Poland) was applied as activator only for the reference rubber compound. Organic zinc salts and complexes, i.e., GluZn with melting point $M_{\mathrm{p}} 175^{\circ} \mathrm{C}$ (Merck, Darmstadt, Germany), RicZn with $M_{\mathrm{p}} 89^{\circ} \mathrm{C}$ (Evonik Industries, Essen, Germany) and AAcZn with $M_{\mathrm{p}} 177^{\circ} \mathrm{C}$ (Riedel-de Haën, Seelze, Germany) were used as alternative vulcanization activators to ZnO. Carbon black N550 provided by Brenntag Polska (Kedzierzyn-Kozle, Poland) was used as a filler. The structures of applied organic zinc activators are presented in Schemes 1-3. 


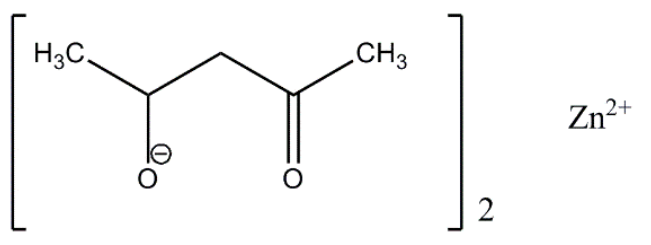

Scheme 1. Structure of zinc acetylacetonate (AAcZn).<smiles>O=C(O)[C@@H](O)[C@@H](O)[C@H](O)[C@H](O)CO</smiles>

Scheme 2. Structure of zinc gluconate (GluZn).<smiles>CCCC[C@H](O)C/C=C\CCCCCCCC(=O)O</smiles>

Scheme 3. Structure of zinc ricinoleate (RicZn).

\subsection{Preparation and Characterization of SBR Compounds}

Using a two-step procedure, SBR compounds with the compositions given in Table 1 were prepared with a laboratory two-roll mill. First, a masterbatch was prepared containing the sulfur, the vulcanization accelerators CBS and MBT, and the filler. Next, the masterbatch was divided into seven equal pieces, and organic zinc activators were added to each of these pieces, with the exception of the reference rubber compound, where $\mathrm{ZnO}$ was introduced. SBR rubber compounds were cured at $160^{\circ} \mathrm{C}$ using the optimal vulcanization time $\left(t_{95}\right)$, which was determined according to the standard PN-ISO 3417:1994 with the D-RPA 3000 rheometer (MonTech, Buchen, Germany).

Table 1. General composition of styrene-butadiene elastomer (SBR) compounds, parts per hundred of rubber (phr) (*alternatively AAcZn, GluZn, RicZn). CBS: N-cyclohexyl-2-benzothiazolesulfenamide; MBT: 2-mercaptobenzothiazole.

\begin{tabular}{ccc}
\hline Components & Reference Sample & $\begin{array}{c}\text { Rubber Compounds with } \\
\text { Organic Zinc Activators }\end{array}$ \\
\hline SBR & 100 & 100 \\
MBT & 1 & 1 \\
CBS & 1 & 1 \\
Sulfur & 2 & 2 \\
Carbon black & 30 & 30 \\
ZnO & 5 & - \\
Organic zinc activator* & - & $3 ; 5$ \\
\hline
\end{tabular}


A differential scanning calorimetry (DSC1) analyzer (Mettler Toledo, Greifensee, Switzerland) was employed to determine the range of SBR vulcanization temperatures and the enthalpy of this process. Measurements were performed in the temperature range of -100 to $250{ }^{\circ} \mathrm{C}$, with a heating rate of $10^{\circ} \mathrm{C} / \mathrm{min}$. Nitrogen was used as the protective gas at a flow rate of $80 \mathrm{~mL} / \mathrm{min}$. Prior to the measurements, the DSC analyzer was calibrated using indium and n-octane as standards. Liquid nitrogen was applied as cooling agent.

According to the standard PN-74/C-04236, the crosslink density of SBR vulcanizates was determined by their equilibrium swelling in toluene, based on the Flory-Rehner equation [29]. The crosslink density was calculated using the Huggins parameter of elastomer-solvent (toluene) interaction [30]

$$
\mu=0.37+0.56 V_{r}
$$

where $V_{r}$ is the volume fraction of elastomer in swollen gel.

The tensile properties of SBR vulcanizates were measured according to the ISO-37 standard procedures using a ZWICK Roell 1435 (Zwick, Ulm, Germany) universal machine. Dumb-bell specimens with a test length of $20 \mathrm{~mm}$ and a width of $4 \mathrm{~mm}$ were used for the measurements. Uniaxial tensile cyclic loading-unloading experiments were performed at room temperature using the same instrument and samples with the same characteristics. The specimens were stretched to $200 \%$ strain and then unloaded to a stress-free state. The loading-unloading cycle was repeated five times and residual strain (permanent set) was produced.

The hardness of disc-shaped SBR materials was determined by Shore's method, according to the standard PN-ISO 868, with an indenter that complies with the standard PN-93/C-04206.

The thermo-oxidative aging of the vulcanizates was performed at $100{ }^{\circ} \mathrm{C}$ for seven days, according to $\mathrm{PN}-82 / \mathrm{c}-04216$. To estimate the resistance of the materials to aging, their mechanical properties and crosslink densities were determined after aging and compared with the values obtained for the vulcanizates before the aging process. The aging factor AF was calculated as the change in the deformation energy of the samples according to Equation (2) [31], where TS is the tensile strength of the vulcanizates and $\mathrm{EB}$ is the elongation at break:

$$
A F=\frac{(E B \cdot T S)_{\text {after aging }}}{(E B \cdot T S)_{\text {before aging }}}
$$

Thermogravimetry (TG) was employed to study the thermal stability of organic zinc activators and vulcanizates. Measurements were performed using a TG/DSC1 analyzer (Mettler Toledo, Greifensee, Switzerland), previously calibrated with standards (indium, zinc). Measurements were carried out in an argon atmosphere (flow rate $50 \mathrm{~mL} / \mathrm{min}$ ), in the temperature range of $25-600{ }^{\circ} \mathrm{C}$, with a heating rate of $20^{\circ} \mathrm{C} / \mathrm{min}$. Next, the gas was changed into air (flow rate $50 \mathrm{~mL} / \mathrm{min}$ ) and samples were heated to $900{ }^{\circ} \mathrm{C}$ with the same heating rate.

Dynamic mechanical measurements were performed in tension mode using a DMA/SDTA861e (Mettler Toledo, Greifensee, Switzerland) analyzer. Measurements were carried out in the temperature range of -100 to $80^{\circ} \mathrm{C}$ with a heating rate of $3{ }^{\circ} \mathrm{C} / \mathrm{min}$, a frequency of $5 \mathrm{~Hz}$, and a strain amplitude of $10 \mu \mathrm{m}$. The temperature of the elastomer glass transition $\left(T_{\mathrm{g}}\right)$ was indicated from the maximum of the $\tan \delta=\mathrm{f}(\mathrm{T})$ curve, where $\tan \delta$ is the loss factor, and $\mathrm{T}$ is the measurement temperature.

SEM images of SBR vulcanizates were taken using an LEO1450 scanning electron microscope (Carl Zeiss AG, Oberkochen, Germany). Prior to the measurement, vulcanizates were broken down using liquid nitrogen. Next, their fractures were coated with a carbon layer and tested. Based on the SEM images, the dispersion of activators and filler particles in the SBR elastomer matrix was analyzed. 


\section{Results and Discussion}

\subsection{Cure Characteristics of SBR Compounds and Crosslink Densities of Vulcanizates}

Rheometer measurements were performed to study the activity of organic zinc salts and complexes during the sulfur vulcanization of SBR compounds. Based on the results, the influences of organic zinc activators on the torque increment during vulcanization, as well as the optimal vulcanization time and scorch time of SBR were determined. Additionally, the crosslink densities of vulcanizates, which correspond to the torque increment during vulcanization of rubber compounds, were determined. The cure characteristics of SBR compounds and crosslink densities of vulcanizates are given in Table 2.

Table 2. Cure characteristics of SBR compounds at $160{ }^{\circ} \mathrm{C}$ and crosslink densities of vulcanizates $\left(\Delta \mathrm{S}\right.$ - torque increment, $\mathrm{t}_{05}$ - scorch time, $\mathrm{t}_{95}$-optimal vulcanization time, $v_{\mathrm{e}}$-crosslink density, standard deviations: $\left.\Delta \mathrm{S} \pm 1.5 \mathrm{dNm}, \mathrm{t}_{05} \pm 0.4 \mathrm{~min} ., \mathrm{t}_{95} \pm 0.5 \mathrm{~min} ., v_{\mathrm{e}} \pm 0.2 \times 10^{-5} \mathrm{~mole} / \mathrm{cm}^{3}\right)$.

\begin{tabular}{|c|c|c|c|c|c|c|}
\hline Activator & $\begin{array}{l}\text { Amount of } \\
\text { Activator } \\
\text { (phr) }\end{array}$ & $\begin{array}{c}\Delta S \\
(\mathrm{dNm})\end{array}$ & $\begin{array}{c}\mathbf{t}_{05} \\
(\mathrm{~min})\end{array}$ & $\begin{array}{c}t_{95} \\
(\mathrm{~min})\end{array}$ & $\begin{array}{l}v_{\mathrm{e}} \cdot 10^{-5} \\
\left(\mathrm{~mole} / \mathrm{cm}^{3}\right)\end{array}$ & $\begin{array}{c}\mathrm{Zn}^{2+} \text { Amount in SBR } \\
\text { Compound (mmole/100 g SBR) }\end{array}$ \\
\hline $\mathrm{ZnO}$ & 5 & 14.3 & 1.1 & 3.0 & 8.8 & 61.5 \\
\hline \multirow{2}{*}{$\mathrm{AAcZn}$} & 3 & 8.5 & 0.9 & 3.0 & 5.9 & 11.4 \\
\hline & 5 & 7.9 & 1.0 & 3.0 & 5.8 & 19.0 \\
\hline \multirow{2}{*}{ GluZn } & 3 & 8.7 & 1.6 & 4.0 & 6.1 & 6.6 \\
\hline & 5 & 8.3 & 2.0 & 4.0 & 5.9 & 11.0 \\
\hline \multirow{2}{*}{ RicZn } & 3 & 9.2 & 1.2 & 2.5 & 6.2 & 4.5 \\
\hline & 5 & 9.5 & 1.6 & 3.0 & 6.3 & 7.6 \\
\hline
\end{tabular}

From the presented data, it follows that SBR compounds crosslinked in the presence of organic zinc activators exhibited lower torque increment during vulcanization compared to that of the SBR containing conventional microsized $\mathrm{ZnO}$. The torque increment is an indirect measure of the degree of elastomer crosslinking. Lower values of $\Delta S$ during vulcanization fully correlate with smaller crosslink densities of vulcanizates containing organic zinc activators. The types and amounts of organic zinc activator did not affect the torque increment considerably and, consequently, the crosslink density of vulcanizates. The lower activity of organic activators in the crosslinking process, resulting in a lower crosslink density of vulcanizates, was due to a much smaller amount of zinc ions introduced into the rubber in the form of organic zinc salts or complexes compared to $\mathrm{ZnO}$. The amount of zinc ions introduced into rubber in the form of particular activators was calculated using their molecular masses and is shown in Table 2. Depending on the type and amount of used organic zinc activator, SBR compounds contained 70-90 wt \% less zinc ions in comparison with the conventionally used 5 phr of $\mathrm{ZnO}$. However, such a small amount of zinc ions seemed to be sufficient to activate sulfur vulcanization of SBR. It should be noticed, that despite the much lower content of zinc ions, organic zinc activators had no detrimental effect on the scorch time or optimal vulcanization time of SBR compounds compared to the conventional $\mathrm{ZnO}$ system. This is very important for the safety of rubber compound processing and economical aspects of vulcanization. The optimal vulcanization time of SBR crosslinked with $\mathrm{ZnO}$ was $3 \mathrm{~min}$., whereas for organic zinc activators, $\mathrm{t}_{95}$ was in the range of $2.5-4.0 \mathrm{~min}$.

Having established the influences of organic zinc salts and complexes on the curing characteristics of SBR compounds, we then studied their influences on the temperature and enthalpy of vulcanization using DSC analysis. The results for SBR compounds are presented in Table 3 and Figures 1 and 2.

The vulcanization of the reference SBR compound containing $\mathrm{ZnO}$ is an exothermic process that occurs in a wide temperature range of $159-218{ }^{\circ} \mathrm{C}$ with a peak temperature of $171{ }^{\circ} \mathrm{C}$ and an enthalpy of $10.6 \mathrm{~J} / \mathrm{g}$. RicZn did not significantly affect the range of vulcanization temperature compared to that of the rubber compound with conventional microsized $\mathrm{ZnO}$. However, widening of the vulcanization temperature range was observed for SBR cured with AAcZn or GluZn, for which the peaks of vulcanization in DSC curves were broad, fuzzy, and asymmetrical. The endset vulcanization 
temperature for SBR crosslinked with $\mathrm{ZnO}$ was $218{ }^{\circ} \mathrm{C}$, whereas a higher endset temperature was determined for the vulcanization of the rubber compound containing AAcZn $\left(229^{\circ} \mathrm{C}\right)$ or GluZn $\left(232^{\circ} \mathrm{C}\right)$. Using $5 \mathrm{phr}$ of these activators increased also the temperature of the vulcanization peak by $13^{\circ} \mathrm{C}$. So, regarding these parameters, $3 \mathrm{phr}$ of studied organic zinc activators was enough to activate the sulfur vulcanization of SBR. Organic zinc salts and complexes had no detrimental effect on the enthalpy of vulcanization. The $\Delta \mathrm{H}$ values for SBR crosslinked with $\mathrm{ZnO}$ or organic zinc activators were equivalent within the range of experimental error.

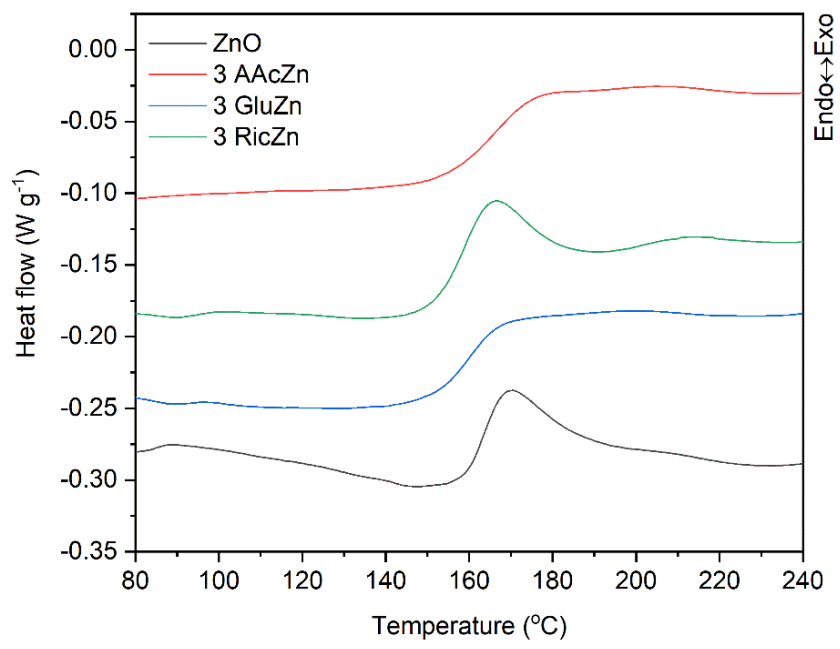

Figure 1. Differential Scanning Calorimetry (DSC) curves of SBR compounds with $3 \mathrm{phr}$ of varying activators.

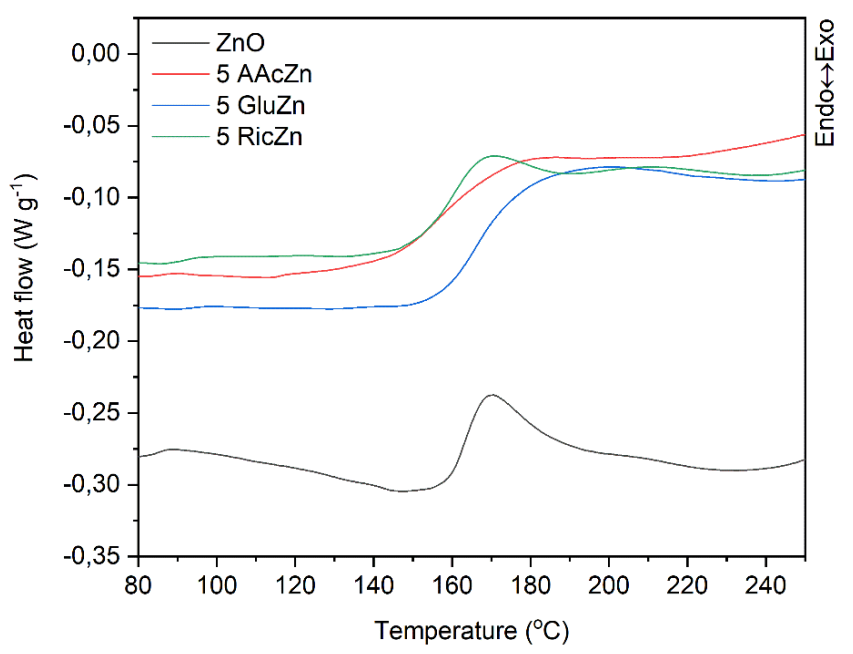

Figure 2. DSC curves of SBR compounds with 5 phr of varying activators.

Table 3. Temperature and enthalpy $(\Delta \mathrm{H})$ of SBR vulcanization measured by DSC (standard deviations: temperature $\pm 2{ }^{\circ} \mathrm{C} ; \Delta \mathrm{H} \pm 1.7 \mathrm{~J} / \mathrm{g}$ ).

\begin{tabular}{ccccc}
\hline Activator & $\begin{array}{c}\text { Amount of } \\
\text { Activator }(\mathbf{p h r})\end{array}$ & $\begin{array}{c}\text { Temperature of } \\
\text { Vulcanization }\left({ }^{\circ} \mathbf{C}\right)\end{array}$ & $\begin{array}{c}\text { Temperature of } \\
\text { Peak }\left({ }^{\circ} \mathbf{C}\right)\end{array}$ & $\Delta \mathbf{H ~ ( J / g )}$ \\
\hline \multirow{2}{*}{ ZnO } & 5 & $159-218$ & 171 & 10.6 \\
\hline \multirow{2}{*}{ AAcZn } & 3 & $158-229$ & 178 & 10.3 \\
& 5 & $155-224$ & 184 & 9.9 \\
\hline \multirow{2}{*}{ GluZn } & 3 & $154-232$ & 175 & 11.9 \\
& 5 & $159-232$ & 184 & 14.7 \\
\hline \multirow{2}{*}{ RicZn } & 3 & $153-220$ & 167 & 12.0 \\
& 5 & $153-223$ & 171 & 12.6 \\
\hline
\end{tabular}


Considering the structure of the organic zinc activators, AAcZn is a zinc chelate complex in which acetylacetonate anion complexes by bonding each oxygen atom to the $\mathrm{Zn}^{2+}$ cation and forms a chelate ring, which may decrease the availability of zinc for reaction with vulcanization accelerators [32]. On the other hand, GluZn is a zinc salt of gluconic acid comprised of two gluconic acid molecules for each $\mathrm{Zn}^{2+}$ cation, whereas Ric $\mathrm{Zn}$ is a zinc salt of ricinoleic acid, which is unsaturated fatty acid. Although the organic zinc activators have different functional groups and molecular mass and, consequently, different content of zinc in $1 \mathrm{~g}$ of the compound, their use resulted in a similar time, temperature, and enthalpy of vulcanization, and the crosslink density of SBR. The differences between the results obtained for organic activators were within the error of measurements. However, taking into account the content of zinc ions, it was concluded that RicZn exhibited the greatest activity during vulcanization. Despite the smallest amount of zinc, RicZn allowed the cure characteristics and crosslink density similar to the elastomer crosslinked with AAcZn or GluZn as activators to be obtained. The ability for reaction with organosulfur and nitrogen compounds, which was reported by Kuhn et al. [27], can also contribute to the best activity of RicZn, since vulcanization accelerators contain sulfur and nitrogen atoms in their molecules. Moreover, the melting point of RicZn is $89^{\circ} \mathrm{C}$, so opposite to AAcZn or GluZn it is in a molten state during vulcanization of SBR compounds at $160^{\circ} \mathrm{C}$. As a result, its mobility in the elastomer matrix during vulcanization was higher than AAcZn or GluZn, which are solids at vulcanization temperature. This facilitates contact between the activator and the particles of sulfur or accelerators, which is crucial to activate the vulcanization.

\subsection{Tensile Properties and Hardness of SBR Vulcanizates}

It is commonly known that the crosslink density affects the mechanical properties of vulcanizates. By analyzing the values of torque increment during vulcanization and the crosslink densities of SBR vulcanizates, it was concluded that organic zinc activators reduced the amount of crosslinks in the elastomer network compared to the conventionally used $5 \mathrm{phr}$ of microsized $\mathrm{ZnO}$, which can affect the tensile properties and hardness of the vulcanizates. Therefore, the influences of organic zinc salts and complexes on mechanical properties, such as the stress at 100\% relative elongation, tensile strength, elongation at break, and hardness of vulcanizates were also examined. The results for SBR vulcanizates are presented in Table 4, whereas the stress-strain curves are shown in Figure 3.

From the data compiled in Table 4, it follows that vulcanizates with organic zinc salts or complexes exhibited approximately 1.2-1.8 MPa lower modulus at relative elongation of $100 \%\left(\mathrm{SE}_{100}\right)$ and about 6-11 ShA lower hardness compared to the reference vulcanizate containing $\mathrm{ZnO}$. This was due to their lower crosslink densities. However, these vulcanizates can be still classified as a medium hardness rubber.

Table 4. Mechanical properties and hardness of SBR vulcanizates ( $\mathrm{SE}_{100}$-modulus at a relative elongation of $100 \%$, TS - tensile strength, EB-elongation at break, $\mathrm{H}$-hardness, standard deviations: $\mathrm{SE}_{100} \pm 0.2 \mathrm{MPa}, \mathrm{TS} \pm 0.9 \mathrm{MPa}, \mathrm{EB} \pm 15 \%, \mathrm{H} \pm 2 \mathrm{ShA}$ ).

\begin{tabular}{cccccc}
\hline Activator & $\begin{array}{c}\text { Amount of } \\
\text { Activator (phr) }\end{array}$ & $\begin{array}{c}\mathbf{S E}_{\mathbf{1 0 0}} \\
\mathbf{( M P a )}\end{array}$ & $\begin{array}{c}\text { TS } \\
\mathbf{( M P a )}\end{array}$ & EB (\%) & $\begin{array}{c}\text { H } \\
\text { (ShA) }\end{array}$ \\
\hline \multirow{2}{*}{ ZnO } & 5 & 4.1 & 12.3 & 212 & 55 \\
\hline \multirow{2}{*}{ AAcZn } & 3 & 2.3 & 19.7 & 350 & 46 \\
& 5 & 2.5 & 20.0 & 346 & 47 \\
\hline \multirow{2}{*}{ GluZn } & 3 & 2.7 & 18.3 & 349 & 48 \\
& 5 & 2.6 & 19.0 & 338 & 49 \\
\hline \multirow{2}{*}{ RicZn } & 3 & 2.9 & 16.8 & 281 & 45 \\
& 5 & 2.8 & 16.0 & 247 & 44 \\
\hline
\end{tabular}




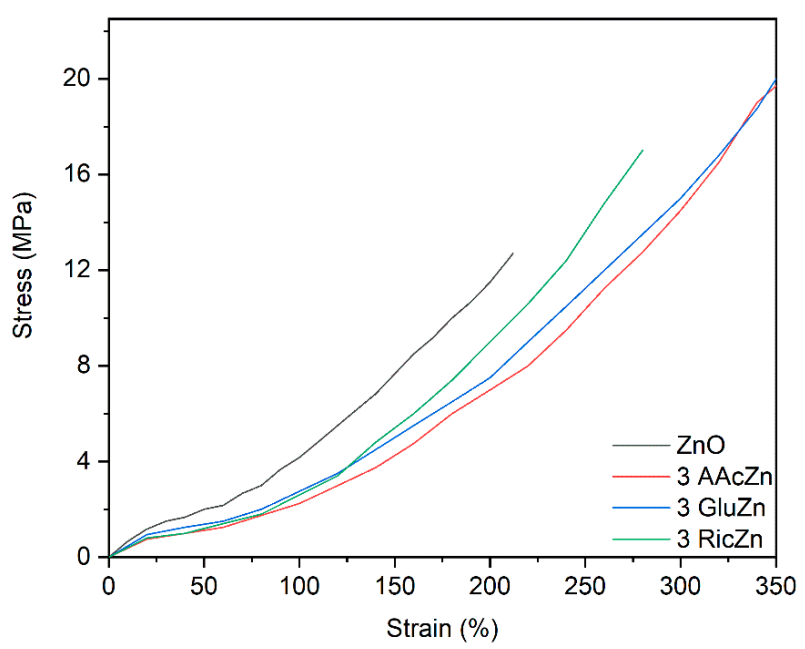

(a)

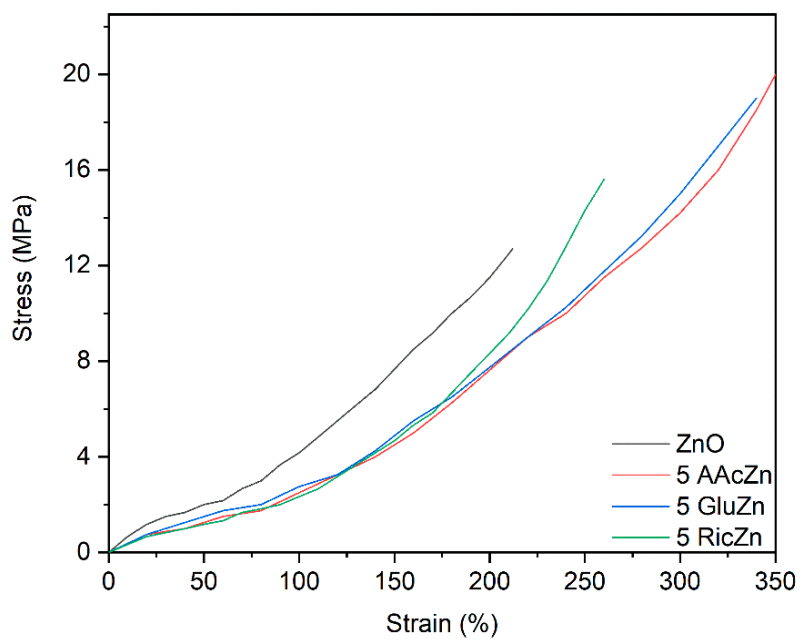

(b)

Figure 3. Stress-strain curves of SBR vulcanizates with varying activators: (a) 3 phr, (b) 5 phr.

On the other hand, organic zinc activators had no detrimental effect on the tensile strength or elasticity of the obtained vulcanizates. The SBR elastomer crosslinked with conventionally used microsized $\mathrm{ZnO}$ exhibited a tensile strength of $12.3 \mathrm{MPa}$ and an elongation at break of $212 \%$. Vulcanizates containing organic zinc activators demonstrated much higher tensile strength, which should be attributed to their low crosslink density. The crosslink density is known to have a significant influence on the mechanical properties of vulcanizates. The decrease in the crosslinks density results in the increase in the elongation at break, and consequently because of the low elongation at break, the TS of vulcanizates increases with the elongation at break. As far as the TS of vulcanizates was concerned, the most effective appeared to be AAcZn and GluZn, for which TS values of approximately $20 \mathrm{MPa}$ and $19 \mathrm{MPa}$ were obtained. On the other hand, the tensile strength of vulcanizate containing RicZn was about 2-3 MPa lower than for other organic zinc activators. The content of organic activator had no influence on the tensile strength of the vulcanizates. It is worth noticing that vulcanizates crosslinked with organic zinc activators, especially AAcZn and GluZn, had a significantly higher elongation at break corresponding to their higher elasticity. The EB values of these vulcanizates were in the range of $338 \%-350 \%$, opposite to RicZn-containing vulcanizates, for which the elongation at break was $240 \%-280 \%$ due to higher crosslink density compared to vulcanizates with AAcZn or GluZn.

Cyclic loading-unloading experiments were performed to study the effect of organic zinc activators on the permanent set of SBR vulcanizates. The obtained stress-strain curves for the first and fifth loading-unloading cycles are presented in Figure 4. 


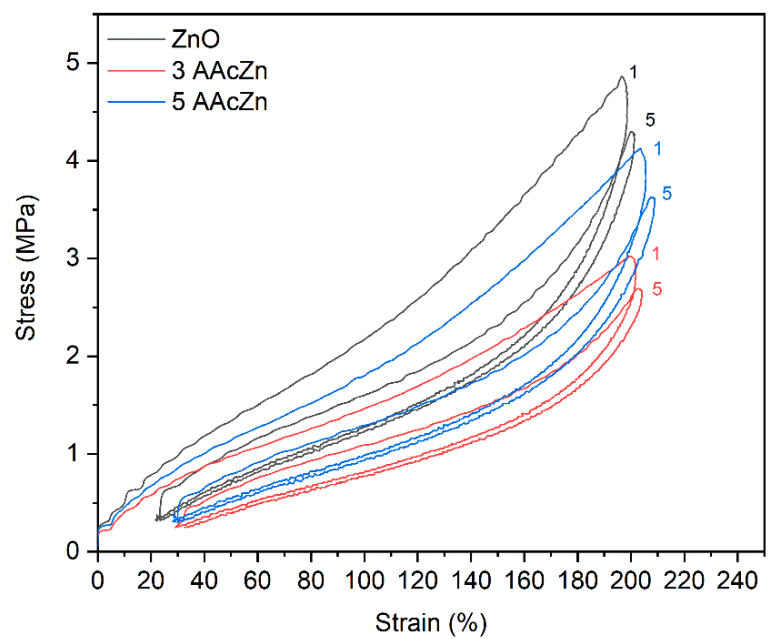

(a)

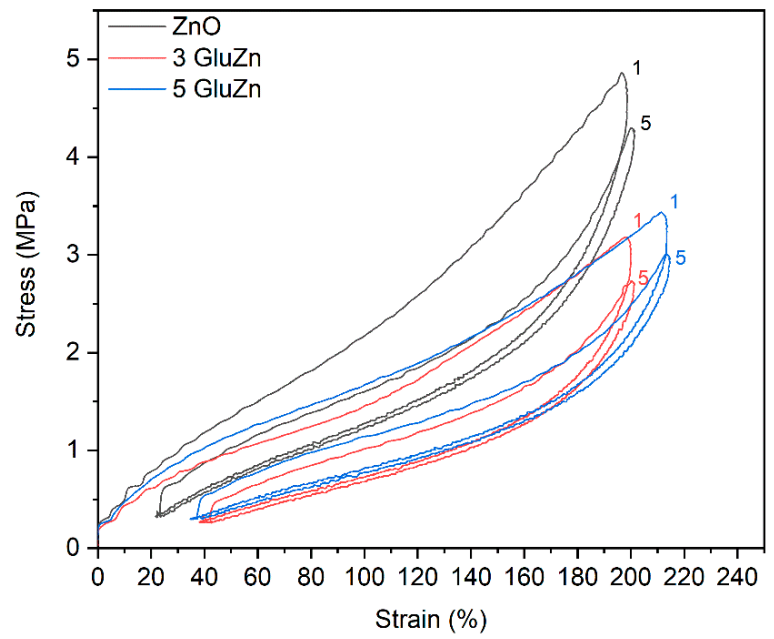

(b)

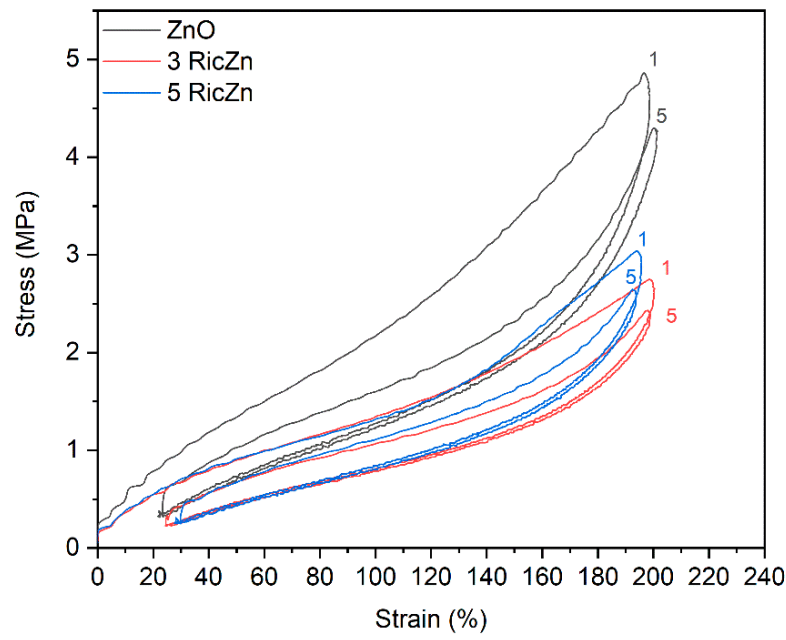

(c)

Figure 4. Stress-strain cyclic loading-unloading curves of SBR vulcanizates with varying activators: 1 , 5-first and fifth loading-unloading cycle, respectively: (a) AAcZn, (b) GluZn, (c) RicZn.

For the loading-unloading cycle, the sample was first loaded to a $200 \%$ strain and then unloaded, and the cycle was repeated five times. Considering the strain values, the unloading curve in each cycle was significantly lower than the corresponding loading curve. Furthermore, the loading curve in each 
subsequent cycle recovered with a bigger strain. The sample did not fully return to its original state when unloaded to a zero stress. The residual strain (permanent set) was produced and determined as the difference between the strain of the last unloading curve and the first (virgin) loading curve [33]. The results for SBR vulcanizates are presented in Table 5.

Table 5. Permanent set of SBR vulcanizates (standard deviation $\pm 2 \%$ ).

\begin{tabular}{ccc}
\hline Activator & Amount of Activator (phr) & Permanent Set (\%) \\
\hline ZnO & 5 & 22 \\
\hline \multirow{2}{*}{ AAcZn } & 3 & 29 \\
& 5 & 27 \\
\hline \multirow{2}{*}{ GluZn } & 3 & 37 \\
& 5 & 35 \\
\hline \multirow{2}{*}{ RicZn } & 3 & 30 \\
& 5 & 32 \\
\hline
\end{tabular}

The residual strain after cyclic loading-unloading experiment of the SBR elastomer crosslinked with microsized $\mathrm{ZnO}$ was $22 \%$. Owing to lower crosslink densities of vulcanizates, the permanent set was shown to be $5 \%-15 \%$ grater when organic zinc activators were used. The lowest permanent set demonstrated vulcanizates with AAcZn, whereas the highest was determined for the GluZn-containing elastomer. The content of organic zinc activators did not affect the permanent set of the vulcanizates. The residual strain of all tested vulcanizates disappeared during storage of the samples for 30 minutes after the end of the loading-unloading experiment.

The studied vulcanizates are filled with carbon black. Therefore, analyzing the strain-stress curves of cyclic loading-unloading presented in Figure 4, the stress-softening phenomenon and stress hysteresis were observed, which were particularly evident in filled vulcanizates [34]. The unloading and reloading curves of studied vulcanizates did not follow the same path and were situated far from the virgin curve, with the subsequent relaxation paths being located each below the previous one. The subsequent load needed to produce the same deformation of the vulcanizate was smaller than that required during the first loading. The stress-softening phenomenon has been extensively studied [35,36]. According to Dannenberg [37] during primary loading of a vulcanized elastomer, which is composed of macromolecular chains, some of the molecular crosslinks or bonds between chains (entanglements) undergo slippage and breaking. During subsequent stress relaxation, some of the broken bonds rearrange and the slippage partially recovers to its original position. Stress-softening is also interpreted as being caused by sliding between polymeric chains and fillers. The macromolecular chains connected to the reinforcing filler particles are slipping and sliding with friction on these particles [35]. As a result, under cyclic loading conditions, studied vulcanizates demonstrated a loss of stiffness resulting in the stress-softening and stress hysteresis. Therefore, the change in the hard and soft domain microstructure can be expected in the studied material, leading to the increase in the soft domain fraction. Considering organic zinc activators, vulcanizates with AAcZn during the cyclic loading-unloading test showed the most similar behavior to the reference sample with $\mathrm{ZnO}$. On the other hand, vulcanizates with RicZn, which exhibited higher crosslink density than the AAcZn or GluZn-containing elastomer, demonstrated the narrowest stress hysteresis and the smallest differences between the stress required to produce the strain of $200 \%$ in the first and in the fifth loading-unloading cycle. Therefore, this vulcanizate exhibited smaller stress-softening under cyclic loading conditions than the rest of the samples tested, resulting from smaller changes in the structure of the elastomer network formed in the vulcanization process, or the internal network formed by filler particles interacting with each other and with elastomer chains.

In summary, despite lower crosslink densities, vulcanizates containing organic zinc activators showed higher tensile strength and elasticity compared to the reference SBR vulcanizate with microsized $\mathrm{ZnO}$. Considering the effects on the mechanical properties and hardness of vulcanizates, the use of $5 \mathrm{phr}$ 
of organic zinc activators was unreasonable, because it did not improve these properties. Therefore, the amount of organic zinc activators could be reduced to $3 \mathrm{phr}$, thus reducing the amount of zinc ions in rubber compounds by 80-90 wt \% compared to $5 \mathrm{phr}$ of microsized zinc oxide. However, it should be noted that vulcanizates obtained with organic zinc activators were softer and less stiff, so they showed a slightly different behavior than the material cured with $\mathrm{ZnO}$. Therefore, these vulcanizates cannot be regarded as a replacement for $\mathrm{ZnO}$-containing material in certain applications.

\subsection{Mechanical Properties of SBR Vulcanizates under Dynamic Conditions}

Dynamic mechanical properties play an essential role in technological applications of SBR compounds due to the fact that rubber products often work under conditions of variable stress and strain. However, regardless of the working conditions, their mechanical properties should be stable during use. Moreover, the ability of rubber composites to dampen vibrations is very important, taking into account their application for manufacturing shock absorbers or elements of vibration dampeners. Therefore, dynamic mechanical analysis (DMA) was employed to determine the influence of organic zinc salts or complexes on the viscoelastic properties of the SBR elastomer and its mechanical loss factor $(\tan \delta)$, which concerns the ability of the material to dampen vibration. DMA measurements were conducted as a function of temperature to study the influence of organic zinc activators on the glass transition $\left(\mathrm{T}_{\mathrm{g}}\right)$ of SBR and its properties in the glassy state and in the rubbery elastic region. The results are presented in Table 6 and Figures 5 and 6.

Table 6. Glass transition temperature $\left(T_{\mathrm{g}}\right)$ and loss factor (tan $\delta$ ) of SBR vulcanizates (standard deviations: $\left.T_{\mathrm{g}} \pm 0.5^{\circ} \mathrm{C}, \tan \delta \pm 0.06\right)$.

\begin{tabular}{|c|c|c|c|c|c|}
\hline Activator & $\begin{array}{c}\text { Amount of } \\
\text { Activator (phr) }\end{array}$ & $\begin{array}{c}T_{\mathrm{g}} \\
\left({ }^{\circ} \mathrm{C}\right)\end{array}$ & $\begin{array}{c}\tan \delta \text { at } \\
T_{\mathrm{g}}(-)\end{array}$ & $\begin{array}{c}\tan \delta \text { at } 25^{\circ} \mathrm{C} \\
(-)\end{array}$ & $\begin{array}{c}\tan \delta \text { at } 50^{\circ} \mathrm{C} \\
(-)\end{array}$ \\
\hline $\mathrm{ZnO}$ & 5 & -38.8 & 1.39 & 0.04 & 0.03 \\
\hline \multirow{2}{*}{ AAcZn } & 3 & -39.2 & 1.38 & 0.11 & 0.09 \\
\hline & 5 & -39.4 & 1.37 & 0.09 & 0.08 \\
\hline \multirow{2}{*}{ GluZn } & 3 & -39.6 & 1.36 & 0.13 & 0.10 \\
\hline & 5 & -39.8 & 1.35 & 0.11 & 0.12 \\
\hline \multirow{2}{*}{ RicZn } & 3 & -39.9 & 1.30 & 0.11 & 0.10 \\
\hline & 5 & -40.5 & 1.36 & 0.13 & 0.06 \\
\hline
\end{tabular}

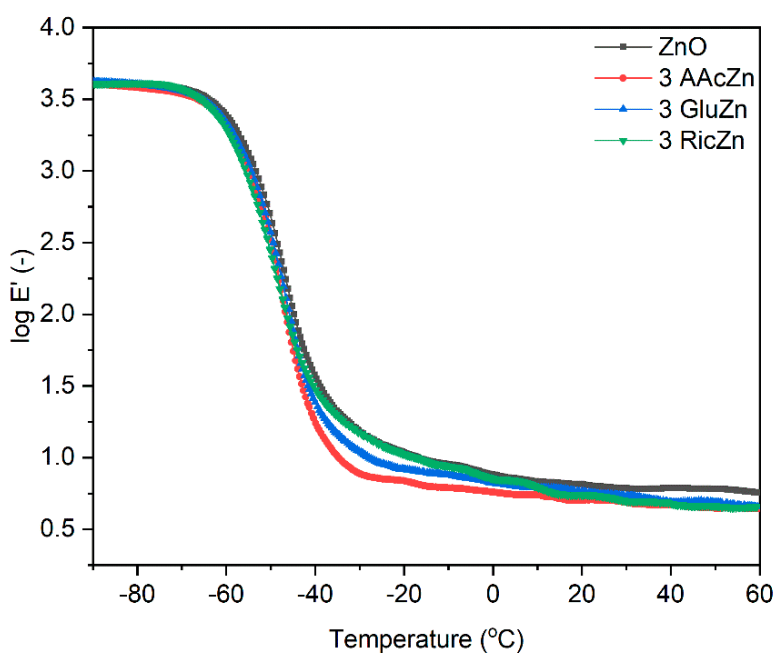

(a)

Figure 5. Cont. 


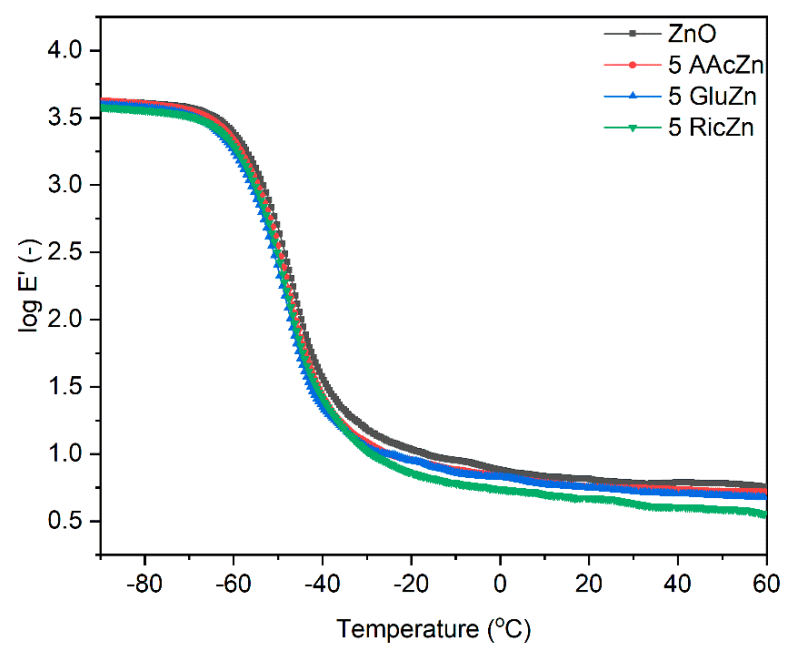

(b)

Figure 5. Storage modulus versus temperature of SBR vulcanizates with varying activators: (a) 3 phr, (b) 5 phr.

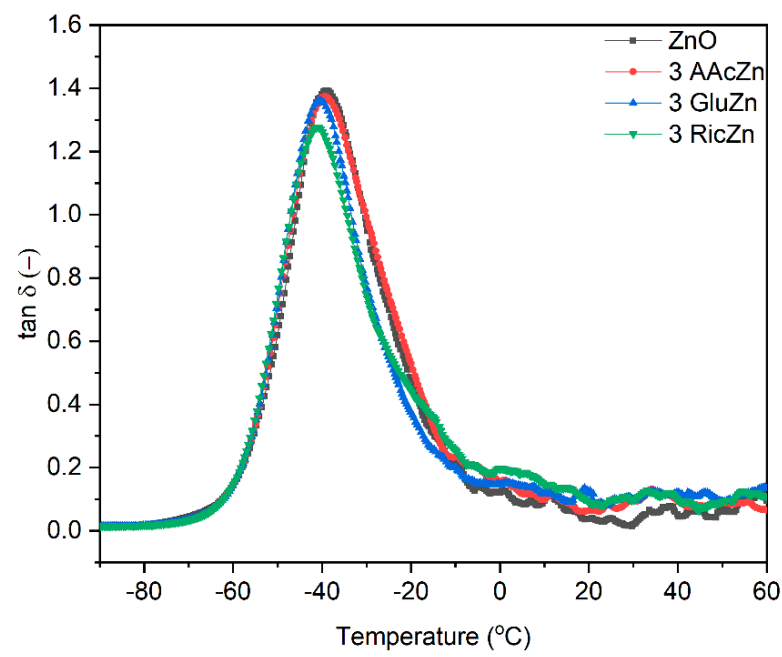

(a)

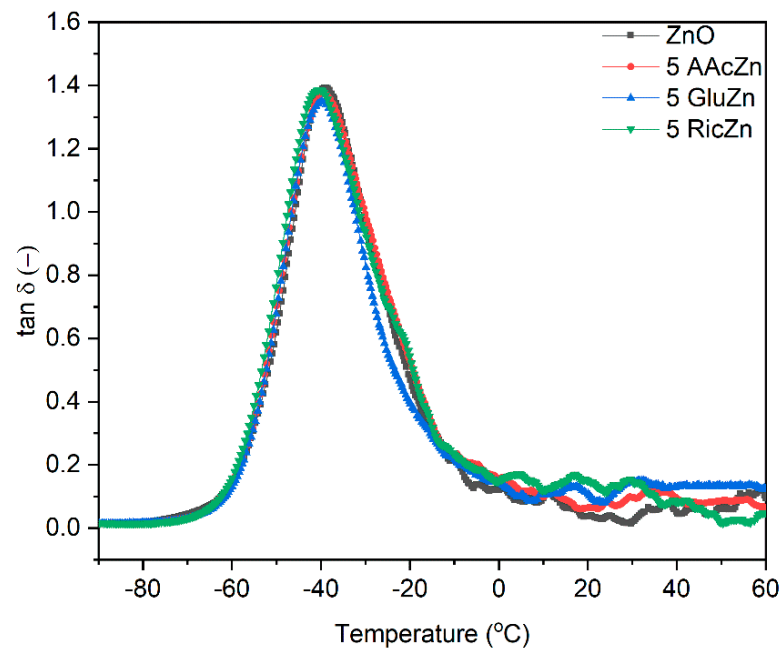

(b)

Figure 6. Loss factor $(\tan \delta$ ) versus temperature of SBR vulcanizates with varying activators: (a) 3 phr, (b) $5 \mathrm{phr}$. 
The maximum $\tan \delta$ in the DMA curve corresponds to the $T_{g}$ temperature of SBR, which was approximately $-38.8^{\circ} \mathrm{C}$ for the vulcanizate containing $\mathrm{ZnO}$. Organic zinc activators did not significantly affect the temperature at which the elastomer went from a hard, glassy state to a rubbery state. It is commonly known that $T_{\mathrm{g}}$ depends on the crosslink density of vulcanizates and increases with crosslinks density due to less molecular mobility of the elastomer chains between the crosslinks. The type and content of organic activator had no significant influence on the crosslink density of vulcanizates and thus on the $T_{\mathrm{g}}$ of SBR. The values of $T_{\mathrm{g}}$ obtained for the reference vulcanizate with $\mathrm{ZnO}$ and for elastomers containing organic zinc salts or complexes were within the range of measurement error.

Regarding the loss factor $\tan \delta$, organic zinc activators, especially RicZn, slightly reduced the value of $\tan \delta$ at $T_{\mathrm{g}}$, but the opposite effect on $\tan \delta$ was achieved in the rubbery elastic region. The values of $\tan \delta$ for SBR containing organic zinc activators were in the temperature range of $25-50{ }^{\circ} \mathrm{C}$ even 2-3 times as high as for elastomers conventionally crosslinked with microsized $\mathrm{ZnO}$. This resulted from lower values of the storage modulus E' of SBR containing alternative activators (Figure 5), which depends on the crosslink density of vulcanizates and decreases proportionally with the number of crosslinks in the elastomer network [38]. Therefore, organic zinc salts or complexes could be expected to improve the damping properties of SBR in the rubbery state. This is another advantage of the use of such vulcanization activators in addition to improved tensile strength and elasticity of vulcanizates. Moreover, vulcanizates containing organic zinc activators demonstrated stable dynamic properties in the temperature range of $25-60^{\circ} \mathrm{C}$, since the loss factor tan $\delta$ did not change considerably as the temperature increased.

\subsection{Dispersion of Curatives and Filler in the SBR Elastomer}

According to the mechanism of sulfur vulcanization proposed by Heideman [1] or Nieuwenhuizen [39], the surface of the activator acts as a catalytic reaction template by activating and joining reactants. Accelerator particles, sulfur, and fatty acids diffuse through the elastomer matrix and are adsorbed onto the activator surface, forming intermediate reactive complexes. Therefore, the contact between particles of activators and accelerators in the elastomer matrix should be maximized to enhance the efficiency of the activator during vulcanization. This contact depends on the activator's particle shape or size. However, the dispersion of activator particles in an elastomer is also very important for the activation of sulfur vulcanization. The agglomeration of activator particles reduces their contact surface with other components of the crosslinking system, and consequently the efficiency of vulcanization. Agglomeration of filler particles reduces its reinforcing effect, since agglomerates may be responsible for local concentration of stresses in vulcanizates subjected to external deformations. Therefore, SEM images were taken to estimate the dispersion degree of curatives and filler particles in the SBR elastomer. Results are presented in Figure 7a-d. 


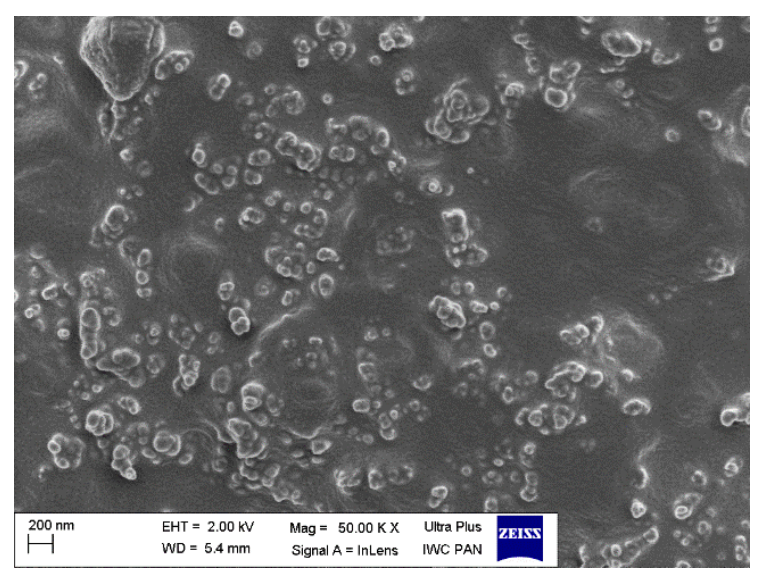

(a)

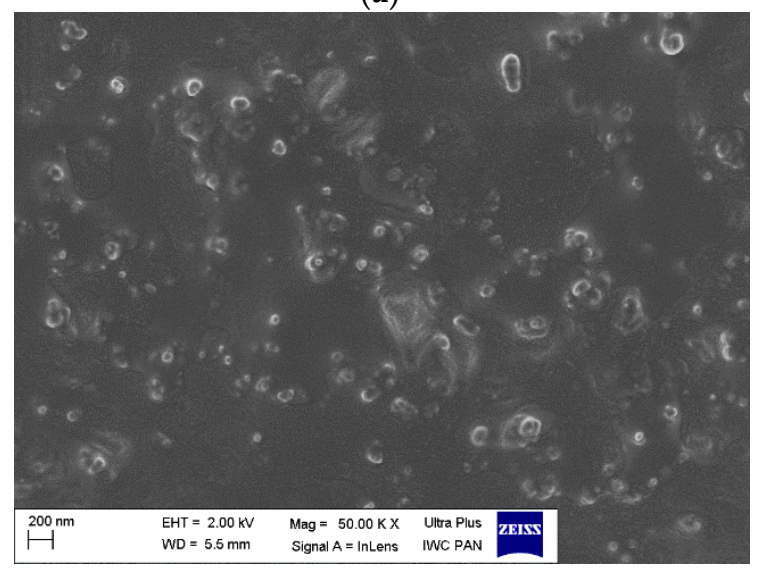

(c)

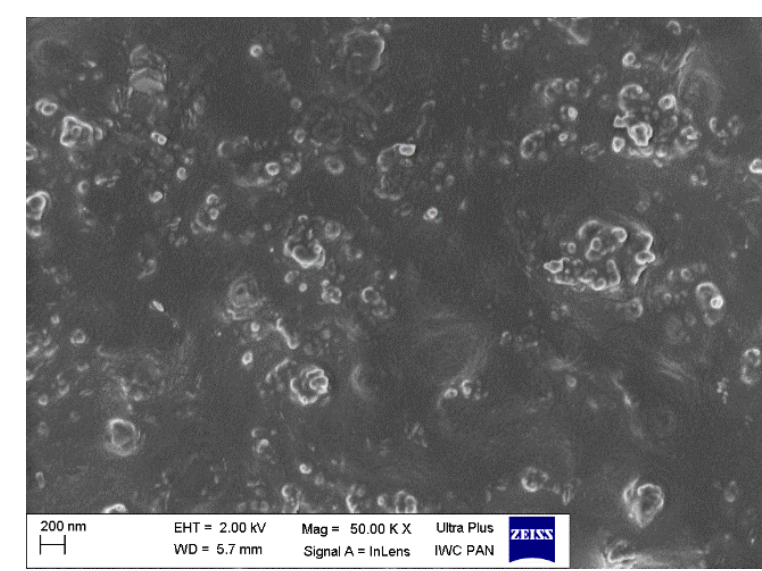

(b)

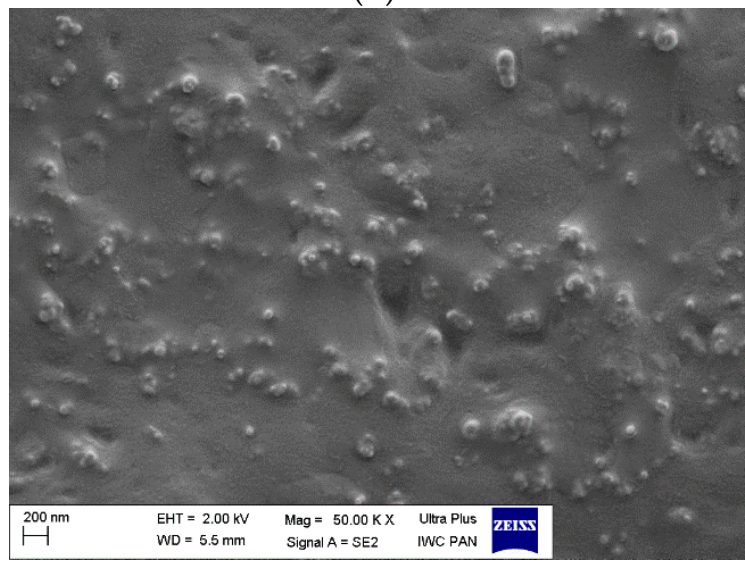

(d)

Figure 7. Scanning electron microscopy (SEM) images of SBR vulcanizates with 5 phr of varying activators: (a) ZnO, (b) AAcZn, (c) GluZn, (d) RicZn.

By analyzing the SEM image of the reference vulcanizate containing $\mathrm{ZnO}$, it was seen that the curatives and filler particles were not homogeneously dispersed in the SBR elastomer. Agglomerates several micrometers in size consisting of nanosized primary particles were created (Figure 7a). However, the agglomerates exhibited good adhesion to the elastomer being surrounded by an elastomeric film that penetrated between the particles, resulting in the good wettability of the agglomerates by elastomer matrix. SEM images showed more uniform dispersion of the curatives and filler particles in the SBR elastomer containing organic zinc activators, compared to vulcanizate with $\mathrm{ZnO}$. In the case of the AAcZn-containing vulcanizate, small aggregates of particles with a size below $1 \mu \mathrm{m}$ were quite homogeneously dispersed and well wetted by the elastomer matrix (Figure $7 \mathrm{~b}$ ). Regarding the GluZn-containing vulcanizate, the dispersion of particles in the SBR was even better than for vulcanizate with AAcZn, and no agglomeration was observed (Figure 7c). It should be noticed that the most homogeneous dispersion of the curatives and filler and the best adhesion of dispersed particles to the elastomer was obtained for the RicZn-containing vulcanizate. In the SEM image presented in Figure $7 \mathrm{~d}$, only individual particles of approximately $200 \mathrm{~nm}$ embedded in the elastomer matrix could be seen. The results of SEM analysis show that not only the change in crosslinks density but also the improvement in the dispersion of the curatives and filler particles could have contributed to the increase in tensile strength, compared to the reference vulcanizate containing $\mathrm{ZnO}$. 


\subsection{Thermal Stability of SBR Vulcanizates}

TG analysis was performed in order to characterize the influence of organic zinc activators and reduction of the zinc ion content in the SBR compounds on the thermal stability of vulcanizates. The temperature required for $5 \%$ mass loss during decomposition $\left(T_{5 \%}\right)$ was determined and taken as the onset decomposition temperature. Furthermore, the temperature of the peak of the differential thermogravimetric (DTG) curves $\left(\mathrm{T}_{\mathrm{DTG}}\right.$ ) was studied. The results are presented in Figures 8 and 9 and summarized in Table 7.
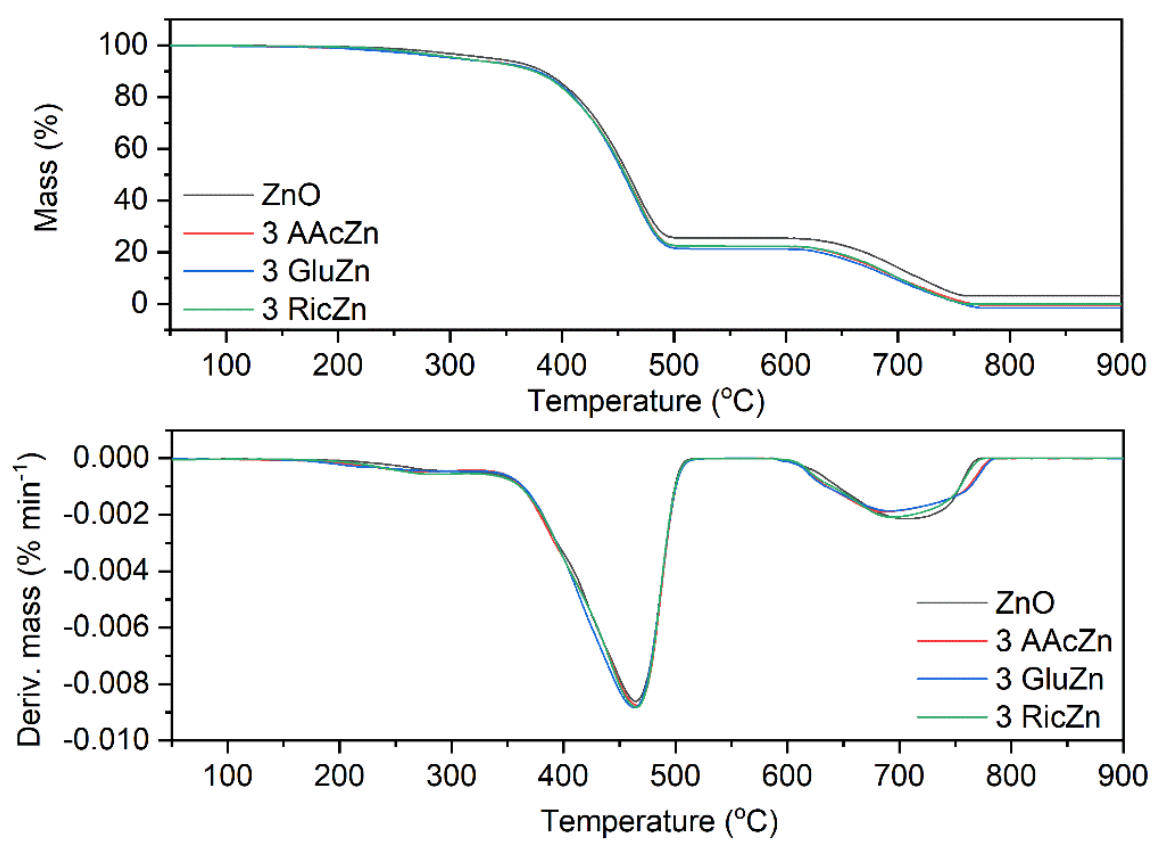

Figure 8. Thermogravimetric (TG) and differential thermogravimetric (DTG) curves of SBR vulcanizates with 3 phr of varying activators.
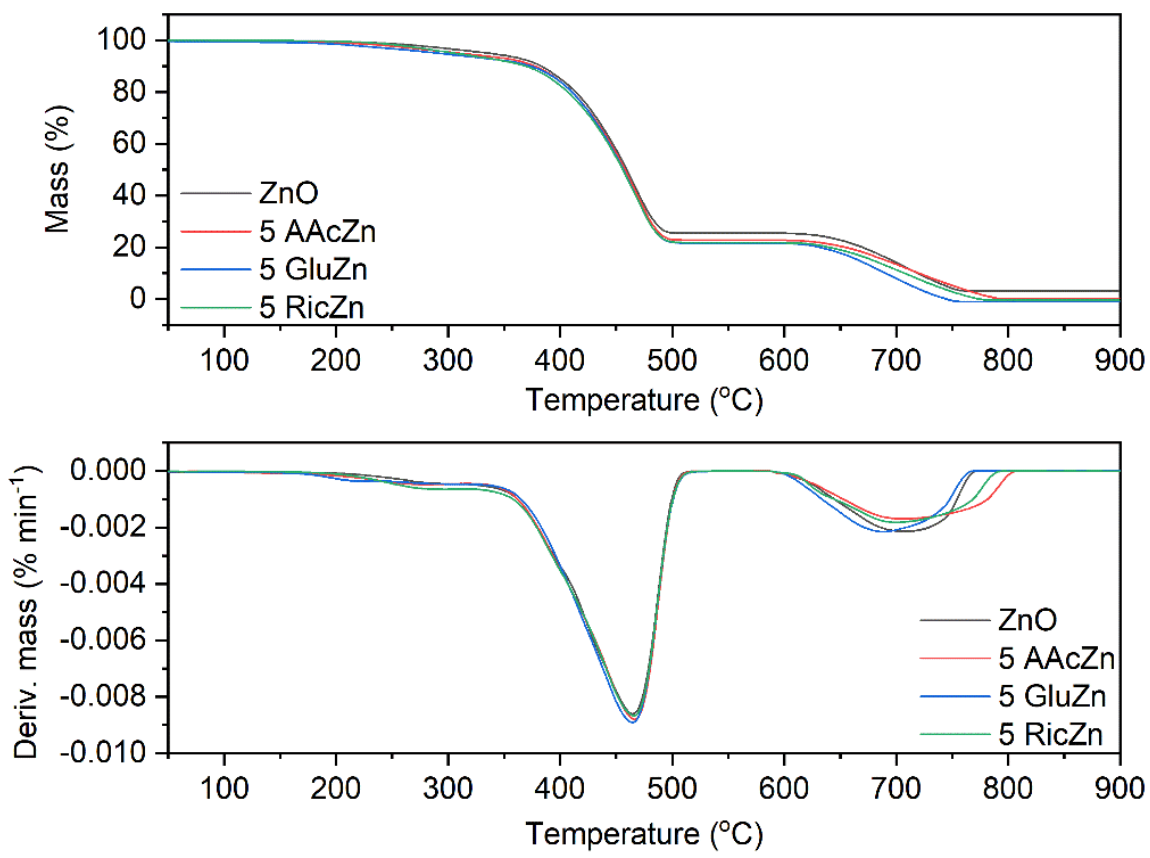

Figure 9. TG and DTG curves of SBR vulcanizates with $5 \mathrm{phr}$ of varying activators. 
Table 7. Decomposition temperature at $5 \%\left(T_{5} \%\right)$ mass change, differential thermogravimetric (DTG) peak temperature $\left(T_{\mathrm{DTG}}\right)$, and total mass loss $(\Delta \mathrm{m})$ during thermal decomposition of SBR vulcanizates (standard deviations: $T_{5 \%} \pm 1.7^{\circ} \mathrm{C}, \mathrm{T}_{\mathrm{DTG}} \pm 1.1^{\circ} \mathrm{C}, \Delta \mathrm{m} \pm 1.5 \%$ ).

\begin{tabular}{|c|c|c|c|c|c|c|c|}
\hline Activator & $\begin{array}{c}T_{5 \%} \text { of } \\
\text { Activator } \\
\left({ }^{\circ} \mathrm{C}\right)\end{array}$ & $\begin{array}{l}\text { Amount of } \\
\text { Activator } \\
\text { (phr) }\end{array}$ & $\begin{array}{l}T_{5 \%} \\
\left({ }^{\circ} \mathrm{C}\right)\end{array}$ & $\begin{array}{c}T_{\mathrm{DTG}} \\
\left({ }^{\circ} \mathrm{C}\right)\end{array}$ & $\begin{array}{c}\Delta \mathrm{m} \\
\left(25-600{ }^{\circ} \mathrm{C}\right) \\
(\%)\end{array}$ & $\begin{array}{c}\Delta \mathrm{m} \\
\left(600-900{ }^{\circ} \mathrm{C}\right) \\
(\%)\end{array}$ & $\begin{array}{l}\text { Residue at } \\
900{ }^{\circ} \mathrm{C}(\%)\end{array}$ \\
\hline $\mathrm{ZnO}$ & - & 5 & 325 & 469 & 74.4 & 22.3 & 3.3 \\
\hline \multirow{2}{*}{ AAcZn } & \multirow{2}{*}{140} & 3 & 303 & 465 & 76.4 & 22.5 & 1.1 \\
\hline & & 5 & 309 & 467 & 77.2 & 22.7 & 0.1 \\
\hline \multirow{2}{*}{ GluZn } & \multirow{2}{*}{106} & 3 & 303 & 465 & 76.3 & 22.6 & 1.1 \\
\hline & & 5 & 301 & 467 & 77.3 & 22.5 & 0.5 \\
\hline \multirow{2}{*}{ RicZn } & \multirow{2}{*}{194} & 3 & 307 & 467 & 76.6 & 22.3 & 1.1 \\
\hline & & 5 & 305 & 467 & 77.4 & 22.2 & 0.4 \\
\hline
\end{tabular}

The TG measurements of vulcanizates were performed in two stages. First, samples were heated from 25 to $600{ }^{\circ} \mathrm{C}$ in an argon atmosphere to achieve a mass loss corresponding to pyrolysis of the elastomer and thermal decomposition of organic additives, such as vulcanization accelerators or activators in the case of vulcanizates containing organic zinc salts or complexes. Therefore, the mass loss in this temperature range was approximately $2 \%-3 \%$ higher for SBR crosslinked with organic zinc activators compared with the reference vulcanizate with microsized $\mathrm{ZnO}$. At a temperature above $600{ }^{\circ} \mathrm{C}$, the measurement atmosphere was changed into air, so the mass losses in the temperature range of $600-900{ }^{\circ} \mathrm{C}$ resulted from the burning of carbon black, which was used as a filler of rubber compounds and was similar for all vulcanizates. At $900{ }^{\circ} \mathrm{C}$, the residue consisted of ash and $\mathrm{ZnO}$ in the case of the reference vulcanizate.

Upon analyzing the thermal stability, the onset decomposition temperature $T_{5 \%}$ determined for vulcanizate containing $\mathrm{ZnO}$ was $325^{\circ} \mathrm{C}$. SBR crosslinked with organic zinc activators exhibited approximately $20^{\circ} \mathrm{C}$ lower $T_{5 \%}$ temperatures. On the other hand, organic zinc salts or complexes did not influence the $\mathrm{T}_{\mathrm{DTG}}$ values, so the temperature of elastomer pyrolysis, which led to major decomposition of the vulcanizates. Therefore, it was concluded that the decrease in $T_{5 \%}$ temperature of vulcanizates was due to lower stability of organic zinc activators, the decomposition of which preceded the pyrolysis of the elastomer. To confirm this conclusion, the onset decomposition temperature $T_{5 \%}$ of organic zinc activators was determined (Table 7). The lowest thermal stability was exhibited by the GluZn, which started decomposition at temperatures above $100{ }^{\circ} \mathrm{C}$. The $T_{5 \%}$ temperature of the most thermally stable organic activator RicZn was $194^{\circ} \mathrm{C}$, while the total weight loss of zinc oxide in the studied temperature range was about $1 \%$ and was determined at a temperature approximately $300{ }^{\circ} \mathrm{C}$, so at the temperature similar to $T_{5 \%}$ of the vulcanizates. A slight reduction in the $T_{5 \%}$ temperature resulting from the use of organic zinc activators should not affect the potential technological applications of tested materials, since they are thermally stable up to a temperature of $300^{\circ} \mathrm{C}$.

\subsection{Resistance of SBR Vulcanizates to Thermo-Oxidative Aging}

Having established that the application of organic zinc activators alternatively to microsized $\mathrm{ZnO}$ did not deteriorate the mechanical properties of vulcanizates under static and dynamic conditions, we then examined their effects on the resistance of the SBR composites to thermo-oxidative aging. Vulcanizates were exposed to the conditions of thermo-oxidative aging at $100^{\circ} \mathrm{C}$ for seven days. Next, their crosslink densities and tensile properties were studied and compared with the values obtained before the aging process. The results are presented in Figures 10 and 11. 


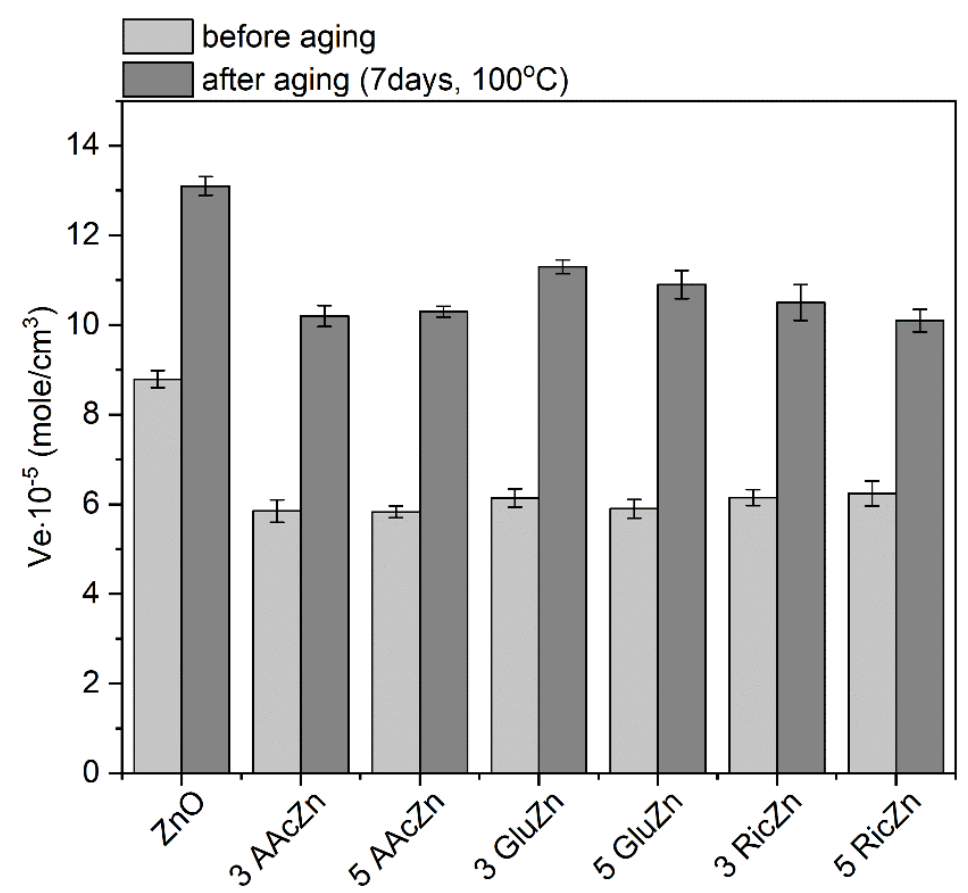

Figure 10. Effect of thermo-oxidative aging on the crosslink density of SBR vulcanizates with varying activators.

Under the influence of an elevated temperature, further crosslinking of the elastomer occurred, resulting in an increased crosslink density of the vulcanizates (Figure 10). A similar effect of thermooxidative aging on the crosslink density has been reported for other elastomers $[31,40,41]$. It should be noted that SBR compounds were vulcanized using optimal vulcanization time $t_{95}$, so the time required for the torque to reach $95 \%$ of the maximum achievable torque. This value relates to the time necessary for the cured rubber to achieve optimal properties. However, this does not mean that the curatives have been totally consumed [42]. Reactive species or radicals after the vulcanization process may still be present in the elastomer and initiate further crosslinking under prolonged exposure to high temperatures. Similar changes in the crosslink density as a result of aging were achieved for the reference vulcanizate containing microsized $\mathrm{ZnO}$ and for elastomer with organic zinc activators. The process of thermo-oxidative aging did not considerably affect the tensile strength of elastomers crosslinked with $\mathrm{ZnO}$, whereas the elongation at break was reduced by $100 \%$ owing to the significant increase in the crosslink density (Figure 11). A similar effect of elevated temperature on TS and EB was observed for the RicZn containing vulcanizate. On the other hand, the tensile strength after aging of the vulcanizates containing other organic zinc activators decreased by 3-4 MPa compared to the TS values before thermo-oxidative aging. The values of their elongation at break were approximately $160 \%-190 \%$ lower than for vulcanizates before the aging process. 


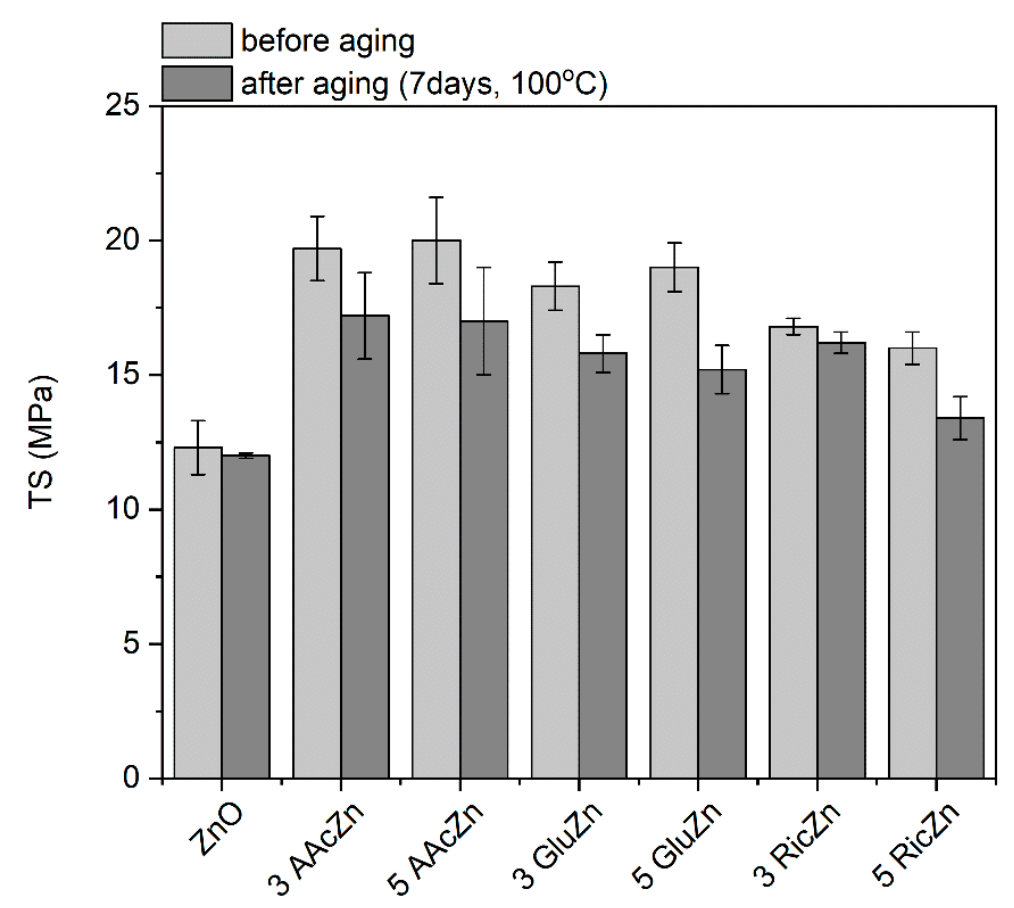

(a)

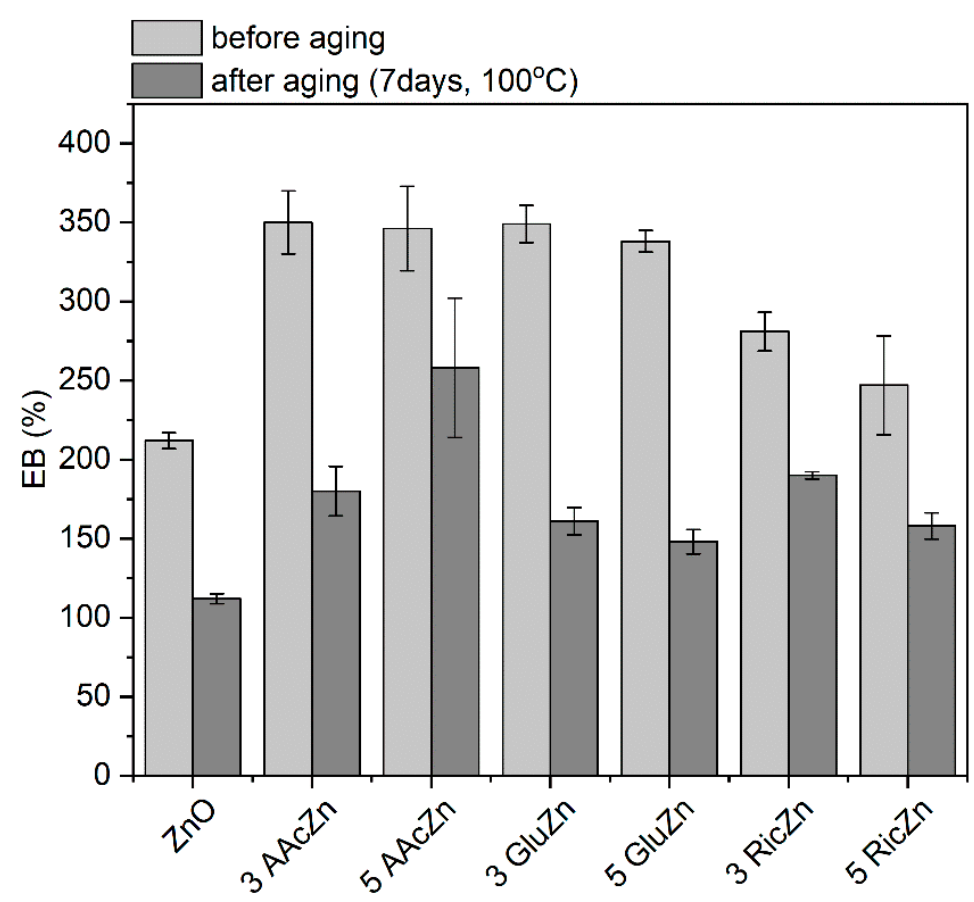

(b)

Figure 11. Effect of thermo-oxidative aging on the mechanical properties of SBR vulcanizates with varying activators: (a) tensile strenght (b) elongation at break.

Based on the collected data, the aging factor (AF) was calculated to quantitatively estimate the changes in the mechanical properties of the vulcanizates due to thermo-oxidative aging (Table 8). This factor is a measurement of the changes in the deformation energy of a sample caused by the aging process. The smaller the changes in the mechanical properties of the vulcanizates due to the aging process, the higher the $\mathrm{AF}$, and as a result, the better resistance of the elastomer to aging. 
Table 8. Aging factor (AF) of SBR vulcanizates (standard deviation: $\mathrm{AF} \pm 0.07$ ).

\begin{tabular}{ccc}
\hline Activator & Amount of Activator (phr) & AF (-) \\
\hline ZnO & 5 & 0.52 \\
\hline \multirow{2}{*}{ AAcZn } & 3 & 0.45 \\
& 5 & 0.46 \\
\hline \multirow{2}{*}{ GluZn } & 3 & 0.40 \\
& 5 & 0.36 \\
\multirow{2}{*}{ RicZn } & 3 & 0.65 \\
& 5 & 0.60 \\
\hline
\end{tabular}

SBR vulcanizates are susceptible to degradation under long-term exposure to elevated temperature. The AF for the reference vulcanizate with $\mathrm{ZnO}$ was 0.52 . By analyzing the effect of organic zinc activators on the aging factor, the highest $A F$ values were found to occur for the vulcanizates containing Ric $Z n-0.65$ and 0.60 , respectively. The application of GluZn activator slightly reduced the aging factor to approximately 0.4. Regarding the measurement error, the AF values for AAcZn-containing vulcanizates were similar to those of the reference sample with microsized $\mathrm{ZnO}$. Taking into account the range of changes in the aging factor of vulcanizates containing organic zinc activators in comparison with a conventionally crosslinked elastomer, it can be concluded that organic activators did not considerably affect the resistance of SBR to thermo-oxidative aging.

\section{Conclusions}

Zinc acetylacetonate and organic zinc salts, such as zinc gluconate and zinc ricinoleate, were used to activate the sulfur vulcanization of SBR.

Organic zinc activators are good alternatives to zinc oxide for the vulcanization of SBR without any detrimental effect on the vulcanization time or temperature. Owing to the 70-90 wt \% smaller amount of zinc ions introduced into the rubber compared with the conventional microsized $\mathrm{ZnO}$, vulcanizates containing organic zinc activators exhibit lower crosslink densities. However, the decrease in the crosslink density of vulcanizates does not deteriorate their tensile properties. Vulcanizates containing organic zinc activators show higher tensile strength and elasticity compared to the SBR vulcanizate with microsized $\mathrm{ZnO}$. Additionally, these vulcanizates showed better damping properties in the rubbery elastic region than conventionally crosslinked elastomers. This is another advantage of the application of the proposed alternative activators. On the other hand, vulcanizates obtained with organic zinc activators were softer and less stiff, and thus demonstrated slightly different mechanical behavior than the rubber cured with $\mathrm{ZnO}$. Therefore, these vulcanizates cannot be regarded as a replacement for $\mathrm{ZnO}$-cured material in certain applications.

Organic zinc salts or complexes do not considerably influence the resistance of SBR to thermo-oxidative aging. A slight reduction of thermal stability resulting from their use should not affect the potential technological applications of tested elastomer materials.

The content of organic zinc activators has no significant effect on the time and temperature of SBR vulcanization, on the crosslink density and properties of vulcanizates; therefore, their amount in rubber compounds could be reduced to 3 phr. Consequently, the amount of zinc ions applied is reduced by 70-90 wt \% compared to zinc oxide. This is particularly relevant, as zinc released to the environment is toxic to aquatic organisms and may cause long-term detrimental effects in the aquatic environment. It should be noted that the rubber industry has a huge global impact. The use of rubber products in the world is constantly growing, from tires and automotive accessories to industrial rubber products, construction applications, medical products, and footwear. Therefore, reducing the use of $\mathrm{Zn}^{2+}$ ions in rubber products is an important ecological goal. The importance of this achievement is underlined by the directives of the European Union, which require the amount of zinc in rubber products to be reduced. 
Author Contributions: Conceptualization, M.M.; methodology, M.M.; software, J.K. and A.S.; validation, M.M.; formal analysis, J.K. and M.M.; investigation, J.K.; resources, M.M.; data curation, J.K. and A.S.; writing-original draft preparation, A.S. and M.M.; writing-review and editing, M.M.; visualization, A.S.; supervision, M.M.; project administration, M.M.; funding acquisition, M.M.

Funding: This research received no external funding.

Conflicts of Interest: The authors declare no conflict of interest.

\section{References}

1. Heideman, G.; Datta, R.N.; Noordermeer, J.W.M.; van Baarle, B. Influence of zinc oxide during different stages of sulfur vulcanization. Elucidated by model compound studies. J. Appl. Polym. Sci. 2005, 95, 1388-1404. [CrossRef]

2. Gaca, M.; Pietrasik, M.; Zaborski, M.; Okrasa, L.; Boiteux, G.; Gain, O. Effect of zinc oxide modified silica particles on the molecular dynamics of carboxylated acrylonitrile-butadiene rubber composites. Polymers 2017, 9, 645. [CrossRef] [PubMed]

3. Przybyszewska, M.; Zaborski, M. The effect of zinc oxide nanoparticle morphology on activity in crosslinking of carboxylated nitrile elastomer. Express Polym. Lett. 2009, 3, 542-552. [CrossRef]

4. Begum, S.P.M.; Yusuff, M.K.K.; Joseph, R. Preparation and use of nano zinc oxide in neoprene rubber. Int. J. Polym. Mater. 2008, 57, 1083-1094. [CrossRef]

5. Owczarek, M.; Zaborski, M. Chlorosulfonated polyethylene elastomers containing zinc oxide incorporated on $\mathrm{SiO}_{2}$. Kaut. Gummi Kunstst. 2004, 57, 218-223.

6. Ebadi-Dehaghani, H.; Reiszadeh, M.; Chavoshi, A.; Nazempour, M.; Vakili, M.H. The effect of zinc oxide and calcium carbonate nanoparticles on the thermal conductivity of polypropylene. J. Macromol. Sci. B 2014, 53, 93-107. [CrossRef]

7. Chapman, A.; Johnson, T. The role of zinc in the vulcanisation of styrene-butadiene rubbers. Kaut. Gummi Kunstst. 2005, 58, 358-361.

8. Pysklo, L.; Pawlowski, P.; Parasiewicz, W.; Slusarski, L. Study on reduction of zinc oxide level in rubber compounds. Part I: Influence of zinc oxide specific surface area and the interphase transfer catalyst 18-crown-6. Kaut. Gummi Kunstst. 2007, 60, 548-553.

9. Maciejewska, M.; Zaborski, M. Effect of ionic liquids on the dispersion of zinc oxide and silica nanoparticles, vulcanisation behaviour and properties of NBR composites. Express Polym. Lett. 2014, 8, 932-940. [CrossRef]

10. Kim, I.J.; Kim, W.S.; Lee, D.H.; Kim, W.; Bae, J.W. Effect of nano zinc oxide on the cure characteristics and mechanical properties of the silica-filled natural rubber/butadiene rubber compounds. J. Appl. Polym. Sci. 2010, 117, 1535-1543. [CrossRef]

11. Coran, A.Y. Chemistry of the vulcanization and protection of elastomers: A review of the achievements. J. Appl. Polym. Sci. 2003, 87, 24-30. [CrossRef]

12. Geyser, M.; McGill, W.J. Thiuram-accelerated sulfur vulcanization. I. The formation of the active sulfurating agent. J. Appl. Polym. Sci. 1996, 60, 425-430. [CrossRef]

13. Heideman, G.; Noordermeer, J.W.M.; Datta, R.N.; van Baarle, B. Effect of zinc complexes ac activator for sulfur vulcanization in various rubbers. Rubber Chem. Technol. 2005, 78, 245-257. [CrossRef]

14. Heideman, G.; Noordermeer, J.W.M.; Datta, R.N.; van Baarle, B. Zinc loaded clay as activator in sulfur vulcanization: A new route for zinc oxide reduction in rubber compounds. Rubber Chem. Technol. 2004, 77, 336-355. [CrossRef]

15. Przybyszewska, M.; Zaborski, M.; Zawadiak, J.; Jakubowski, B. Zinc chelates as new activators for sulphur vulcanization of acrylonitrile-butadiene rubber. Express Polym. Lett. 2009, 3, 256-266. [CrossRef]

16. Pastusiak, M.; Dobrzynski, P.; Kaczmarczyk, B.; Kasperczyk, J.; Smola, A. The polymerization mechanism of lactide initiated with zinc (II) acetylacetonate monohydrate. Polymer 2011, 52, 5255-5261. [CrossRef]

17. Dorzynski, P.; Pastusiak, M.; Bero, M. Less toxic aacetylacetonates as initiators of trimethylene carbonate and 2,2-trimethyldimethylene carbonate ring opening polymerization. J. Polym. Sci. Pol. Chem. 2005, 43, 1913-1922. [CrossRef]

18. Hamerton, I.; Brendan, J.; Howlin, P.J. Metals and coordination compounds as modifiers for epoxy resins. Coord. Chem. Rev. 2002, 224, 67-85. [CrossRef] 
19. Code of Federal Regulations no. 21CFR182.8988, Title 21-Food and Drugs, Chapter 1—Food and Drug Administration Department of Health and Human Servises, Subchapter B-Food for Human Consumption. 1 April 2018.

20. Wegmuller, R.; Tay, F.; Zeder, F.; Benic, M.; Hurrell, R.F. Zinc absorption by young adults from supplemental zinc citrate is comparable with that from zinc gluconate and higher than from zinc oxide. J. Nutr. 2014, 144, 132-136. [CrossRef]

21. Gupta, M.; Mahajan, V.K.; Mehta, K.S.; Chauhan, P.S. Zinc therapy in dermatology: A review. Dermatol. Res. Pract. 2014, 709152. [CrossRef]

22. Tuner, R.B.; Cetnarowski, W.E. Effect of treatment with zinc gluconate or zinc acetate on experimental and natural colds. Clin. Infect. Dis. 2000, 31, 1202-1208. [CrossRef] [PubMed]

23. Heckmann, S.M.; Hujoel, P.; Habiger, S.; Friess, W.; Wichmann, M.; Heckmann, J.G.; Hummels, T. Zinc gluconate in the treatment of dysgeusia-A randomized clinical trial. J. Dent. Res. 2005, 84, 35-38. [CrossRef] [PubMed]

24. Duncan-Lewis, C.A.; Lukman, R.L.; Banks, R.K. Effects of zinc gluconate and 2 other divalent cationic compounds on olfactory function in mice. Comp. Med. 2011, 61, 361-365. [PubMed]

25. Zekorn, R. Zinc ricinoleate: The basis of its deodorizing activity. Cosmet. Toilet. 1997, 112, 37-40.

26. Zekorn, R. Deodorants based on zinc ricinoleate. Parf. Kosmet. 1996, 77, 682-684.

27. Kuhn, H.; Müller, F.; Peggau, J.; Zekorn, R. Mechanism of the odor-adsorption effect of zinc ricinoleate. A molecular dynamics computer simulation. J. Surfactants Deterg. 2000, 3, 335-343. [CrossRef]

28. Final report on the safety assessment of Ricinus communis (Castor) seed oil, hydrogenated Castor oil, glyceryl ricinoleate, glyceryl ricinoleate $\mathrm{SE}$, ricinoleic acid, potassium ricinoleate, sodium ricinoleate, zinc ricinoleate, cetyl ricinoleate, ethyl ricinoleate, glycol ricinoleate, isopropyl ricinoleate, methyl ricinoleate, and octyldodecyl ricinoleate. Int. J. Toxical. 2007, 26, 31-77. [CrossRef]

29. Flory, P.J.; Rehner, J. Statistical mechanics of cross-linked polymer networks. II. Swelling. J. Chem. Phys. 1943, 11, 521-526. [CrossRef]

30. Furuta, I.; Kimura, S.; Iwama, M. Physical constants of rubbery polymers. In Polymer Handbook, 4th ed.; Brandrup, J., Immergut, E.H., Grulke, E.A., Eds.; John Wiley \& Sons Inc: New York, NY, USA, 1999; pp. 1-7.

31. Maciejewska, M.; Zaborski, M. Ionic liquids as coagents for sulfur vulcanization of butadiene-styrene elastomer filled with carbon black. Polym. Bull. 2018, 75, 4499-4514. [CrossRef]

32. Ambrožič, G.; Škapin, S.D.; Žigon, M.; Orel, Z.C. The synthesis of zinc oxide nanoparticles from zinc acetylacetonate hydrate and 1-butanol or isobutanol. J. Colloid Interf. Sci. 2010, 346, 317-323. [CrossRef]

33. Huang, L.; Yang, X.; Gao, J. Pseudo-elastic analysis wit permanent set in carbon-filled rubber. Adv. Polym. Tech. 2019, 2369329. [CrossRef]

34. Rickaby, S.R.; Scott, N.H. The cyclic stress softening model for the Mullins effect. Ind. J. Solids Struct. 2013, 50, 111-120. [CrossRef]

35. Cantournet, S.; Desmorat, R.; Besson, J. Mullins effect and cyclic stress softening of filled elastomers by internal sliding and friction thermodynamics model. Ind. J. Solids Struct. 2009, 46, 2255-2264. [CrossRef]

36. Diani, J.; Fayolle, B.; Gilormini, P. A review on the Mullins effect. Eur. Polym. J. 2009, 45, 601-612. [CrossRef]

37. Dannenberg, E.M. Molecular slippage mechanism of reinforcement. Trans. Inst. 1966, 42, $26-42$.

38. Zosel, A.; Ley, G. Influence of cross-linking on structure, mechanical properties, and strength of latex films. Macromolecules 1993, 26, 2222-2227. [CrossRef]

39. Nieuwenhuizen, P.J. Zinc accelerator complexes: Versatile homogeneous catalysts in sulfur vulcanization. Appl. Catal. A Gen. 2001, 207, 55-68. [CrossRef]

40. Kruželák, J.; Dosoudil, R.; Hudec, I. Thermooxidative aging of rubber compounds based on NR and NBR with incorporated strontium ferrite. J. Elastom. Plast. 2018, 50, 71-91. [CrossRef]

41. Gwaili, S.E.; Badawy, M.M.; Hassan, H.H.; Madani, M. Influence on thermal aging on crosslinking density of boron carbide/natural rubber composites. Polym. Test. 2003, 22, 3-7. [CrossRef]

42. Simpson, R.B. Rubber Basics; Rapra Technology Limited: Shawbury, UK, 2002.

(C) 2019 by the authors. Licensee MDPI, Basel, Switzerland. This article is an open access article distributed under the terms and conditions of the Creative Commons Attribution (CC BY) license (http://creativecommons.org/licenses/by/4.0/). 